\title{
Monitoring of a Full-Scale Embankment Experiment Regarding Soil-Vegetation-Atmosphere Interactions
}

\author{
Raül Oorthuis * (D), Marcel Hürlimann ${ }^{(0)}$, Alessandro Fraccica, Antonio Lloret ${ }^{\mathbb{D}}$, José Moya, \\ Càrol Puig-Polo ${ }^{(\mathbb{B})}$ and Jean Vaunat ${ }^{(\mathbb{B})}$ \\ Division of Geotechnical Engineering and Geosciences, Department of Civil and Environmental Engineering, \\ UPC BarcelonaTECH, 08034 Barcelona, Spain; marcel.hurlimann@upc.edu (M.H.); \\ alessandro.fraccica@upc.edu (A.F.); antonio.lloret@upc.edu (A.L.); jose.moya@upc.edu (J.M.); \\ carol.puig@upc.edu (C.P.-P.); jean.vaunat@upc.edu (J.V.) \\ * Correspondence: raul.oorthuis@upc.edu
}

Received: 21 March 2018; Accepted: 19 May 2018; Published: 25 May 2018

\begin{abstract}
Slope mass-wasting like shallow slides are mostly triggered by climate effects, such as rainfall, and soil-vegetation-atmosphere (SVA) interactions play a key role. SVA interactions are studied by a full-scale embankment with different orientations (North and South) and vegetation covers (bare and vegetated) in the framework of the prediction of climate change effects on slope stability in the Pyrenees. A clayey sand from the Llobregat river delta was used for the construction of the embankment and laboratory tests showed the importance of suction on the strength and hydraulic conductivity. Sixty sensors, which are mostly installed at the upper soil layer of the embankment, registered 122 variables at four vertical profiles and the meteorological station with a 5 min scan rate. Regarding temperature, daily temperature fluctuation at the shallow soil layer disappeared at a depth of about $0.5 \mathrm{~m}$. There was great influence of orientation with much higher values at the South-facing slope (up to $55^{\circ} \mathrm{C}$ at $-1 \mathrm{~cm}$ depth) due to solar radiation. Regarding rainfall infiltration, only long duration rainfalls produced an important increase of soil moisture and pore water pressure, while short duration rainfalls did not trigger significant variations. However, these changes mostly affected the surface soil layer and decreased with depth.
\end{abstract}

Keywords: monitoring; embankment; rainfall infiltration; heat flux

\section{Introduction}

The understanding of soil-vegetation-atmosphere interactions is fundamental for the correct assessment of rainfall-induced slides and other slope mass-wasting processes [1]. These interactions are of great importance due to future global changes associated with climate changes [2-5]. The fifth assessment report of the Intergovernmental Panel on Climate Change [6] states that number of warm days has likely increased at the global level and that extreme precipitation events have increased in Europe since 1950. All these effects will largely affect the soil-vegetation-atmosphere interactions and also influence the mechanisms of slope mass-wasting in the future $[7,8]$.

Mass-wasting due to shallow slope failures represents one of the most important erosional process in many mountainous regions and may also be the most dangerous [9]. In addition, superficial failures in artificial slopes are a particularly important issue at transportation embankments [10-12].

Soil-vegetation-atmosphere (SVA) models have generally received little attention in geotechnical engineering, maybe due to the absence of thermo-hydro-mechanical formulations able to couple all the processes with the soil mechanical response. With the exception of some pioneering work such as Blight [13], it is only in recent years that research has developed on the overall effect of the SVA interactions on responses of natural and artificial slopes [14-16]. However, most studies focus on 
the infiltration processes in unsaturated soils by performing laboratory tests on slopes with limited extension [17-19]. There are also some large-scale experiments [20] and a few studies that constructed a full-scale embankment in order to monitor the soil-atmosphere interactions [21-23]. Finally, multiple research studies have been performed on the monitoring of natural slopes affected by different types of slope mass-wasting mechanisms [24-27].

The preceding state-of-the-art techniques show that most research focuses on the soil-atmosphere interaction and studies on SVA mechanisms are rather scare. There are studies regarding soil-vegetation interactions [28], but principally neglecting geotechnical aspects. These aspects, such as the effect of suction and root reinforcement on the shear strength, are important to evaluate the engineering behavior of earth materials and the stability of natural and man-made slopes [29]. Therefore, the principal goal of our study is to achieve detailed data on the SVA interactions by performing an extensive monitoring of a full-scale physical embankment located close to our university. The registered data will improve our understanding about the thermo-hydraulic processes occurring at the soil-plants-atmosphere interface and their coupling with mechanical effects. In the present publication, we describe the monitoring set-up and present the first monitoring results on the heat and water flow across the upper soil layer of the test embankment.

\section{Methods}

\subsection{Construction of Embankment}

At the end of 2016, the test embankment was built with help of a backhoe loader at the ParcUPC Agròpolis, which includes outdoor experimental facilities for research purposes. It is situated on the deltaic floodplain of the Llobregat River about $20 \mathrm{~km}$ southwest from Barcelona downtown. The embankment was made using a clayey sand of the zone.

The embankment measures $18 \mathrm{~m}$ long, $12 \mathrm{~m}$ wide, and $2.5 \mathrm{~m}$ high, which incorporates a total volume of about $326 \mathrm{~m}^{3}$. The slopes are built at 33.7 degrees, corresponding to $3 \mathrm{H}: 2 \mathrm{~V}$. The construction phases included three steps: first, the core was built; then an irregular, studded structured, and impermeable polyethylene geomembrane was laid out; and finally, a 50-70 cm thick soil layer was accumulated on the geomembrane. A shallow soil layer on an impermeable bedrock is a very common condition in many mountainous areas including the Pyrenees or the Catalan Coastal Ranges, where multiple slope rainfall-induced failures have occurred in the past [30-32]. Figure 1a shows a photograph of the embankment during the accumulation of the surficial soil layer on the geomembrane.

The surficial soil layer includes four monitored slope partitions, which are laterally separated by the geomembrane: a vegetated and a bare slope at the South side of the embankment and another two partitions with and without vegetation at the North-facing slope. This set-up provided information on the effect of orientation (solar radiation) and of vegetation, two fundamental aspects in the evaluation of the influence of future changes on slope mass-wasting. The growth of vegetation was impeded in two partitions by the periodic application of herbicide, while Cynodon Dactylon and Festuca Arundinacea seeds were sowed in the other two partitions. These species are common in the application of slope revegetation, are resistant against drought, and increase soil strength due to their roots [33-36].

In addition, displacement measurements by different geomatic techniques are performed periodically to observe ground movements. At the moment, terrestrial laser scanning (Figure 1b) and dual constellation real-time kinematic positioning with GPS were used. In the future, digital photogrammetry using data of time-lapse cameras is planned to achieve movements with a smaller time interval. 
(a)

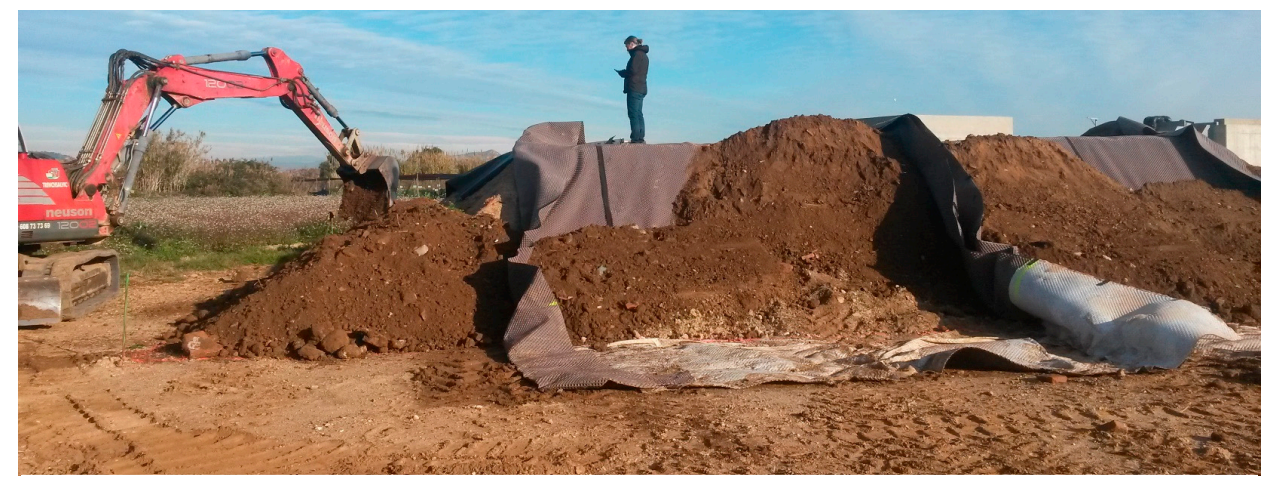

(b)

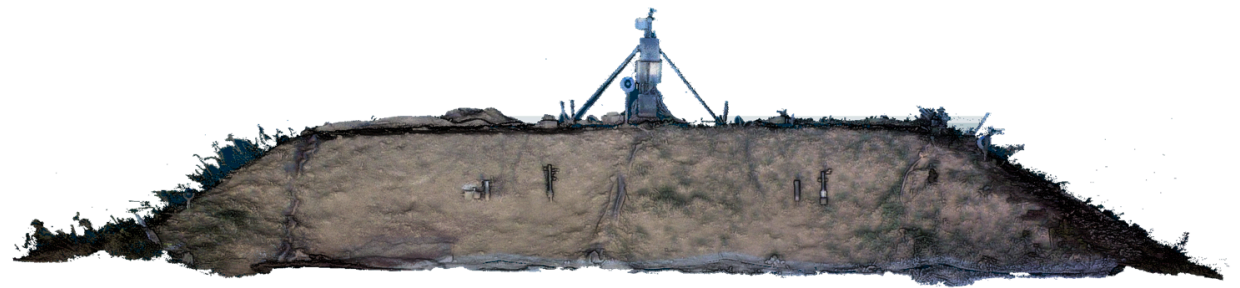

Figure 1. (a) Photograph of the embankment during the construction; (b) 3D view of the point cloud obtained by terrestrial laser scanning.

\subsection{Soil Sampling and Laboratory Tests}

Different soil samples of the material used for the construction of the embankment from the Llobregat river delta were taken prior to and during the development of the experiment. A detailed test program was performed at a geotechnical laboratory focusing on the basic, hydraulic, and mechanical characterization of the soil. The different laboratory tests included: (i) particle-size distribution by sieve and sedimentation methods [37,38], (ii) Atterberg limits [39], (iii) permeability, (iv) specific gravity (by pycnometer method) [40], (v) direct shear tests (in shear box device) [41], and (vi) soil-water retention curve.

Estimation of the soil permeability is important for the correct understanding of the hydro-mechanical behavior of the embankment. However, it must be stated that laboratory measurements of a small sample may be different from field permeability, where heterogeneities in the soil mostly exist [42]. For example, small movements in the slope can produce cracks that greatly increase vertical permeability.

The saturated hydraulic conductivity was determined in the laboratory by different tests: (i) triaxial tests with constant back pressure, (ii) constant and variable head permeameter tests, and (iii) consolidation tests in saturated consolidation by using the oedometer apparatus.

Multiple direct shear tests were performed to determine the strength parameters of the soil including four consolidated drained (CD) tests in saturated conditions, and $15 \mathrm{CD}$ tests at constant water content under partially saturated conditions. Normal stress applied to the samples was up to about $30 \mathrm{kN} / \mathrm{m}^{2}$, which roughly corresponds to a $1.7 \mathrm{~m}$ thick soil layer, using the density of the materials under consideration. Samples were statically compacted until they reached the specified dry density $\left(\rho_{d}=15.5 \pm 0.7 \mathrm{Mg} / \mathrm{m}^{3}\right)$ using three different water contents $(15 \%, 19 \%$, and $25 \%)$.

The soil-water retention curve (SWRC) was achieved by different methods. The relation between soil suction and soil volumetric water content is important information to understand the hydro-mechanical behavior of unsaturated soils [43]. The SWRC was measured in the laboratory using drying/wetting cycles on samples with a dry density of $1.62 \mathrm{Mg} / \mathrm{m}^{3}$. On one side, a standard ceramic tip laboratory tensiometer (T5x, UMS, München, Germany) was used for low suction values up to $200 \mathrm{kPa}$. On the other side, a dielectric water potential sensor (MPS-6, Decagon Devices, Pullman, WA, USA) and a chilled mirror dew point hygrometer (WP4, Decagon Devices, Pullman, WA, USA) were applied to measure high suction values up to 100 and 300 MPa respectively. 
After constructing the embankment, in situ undisturbed soil block samples were taken at several depths between 5 and $20 \mathrm{~cm}$, in order to determine moisture and natural/dry bulk density. These undisturbed soil samples were obtained from thin-walled sampling tubes and clods. Since the monitoring is installed at the two principal orientations (North and South) of the embankment, material was sampled at these two slope faces. The paraffin method [44] was applied to measure the density of these undisturbed samples.

\subsection{Monitoring Set-Up}

The sensors were installed at vertical infiltration profiles inside the upper soil layer of each of the four partitions. In addition, a meteorological station was fixed at the top of the embankment. All the sensors are connected by wires to a datalogger (CR1000, Campbell Scientific, Logan, UT, USA) that was used in combination with two multiplexers due to the large amount of sensors. The data of all sensors are recorded at a constant sampling rate of $5 \mathrm{~min}$. Every $24 \mathrm{~h}$, the data files are sent via FTP to the university sever. The power supply of the entire monitoring system is provided by solar panels and batteries.

The experiment includes four different zones: (i) South slope with vegetation (SV), (ii) South slope without vegetation $(\mathrm{SnV})$, (iii) North slope with vegetation (NV), (iv) North slope without vegetation $(\mathrm{NnV})$. Each of the four zones is equipped by a vertical profile of different sensors (Figure 2) and the devices that measure the surface runoff and seepage. Thus, a complete analysis of the soil-vegetation-atmosphere interaction is possible by incorporating observations gathered by the meteorological station. The installation of the sensors was performed in two main phases. First, the setup of the non-vegetated profiles ( $\mathrm{SnV}$ and $\mathrm{NnV}$ ) was performed in spring 2017. Second, the vegetated profiles (SV and NV) were installed in autumn 2017. Finally, some complementary sensors were mounted at the beginning of 2018. Figure 3 shows a photograph of the embankment after the installation of the sensors looking towards the North-faced slope.

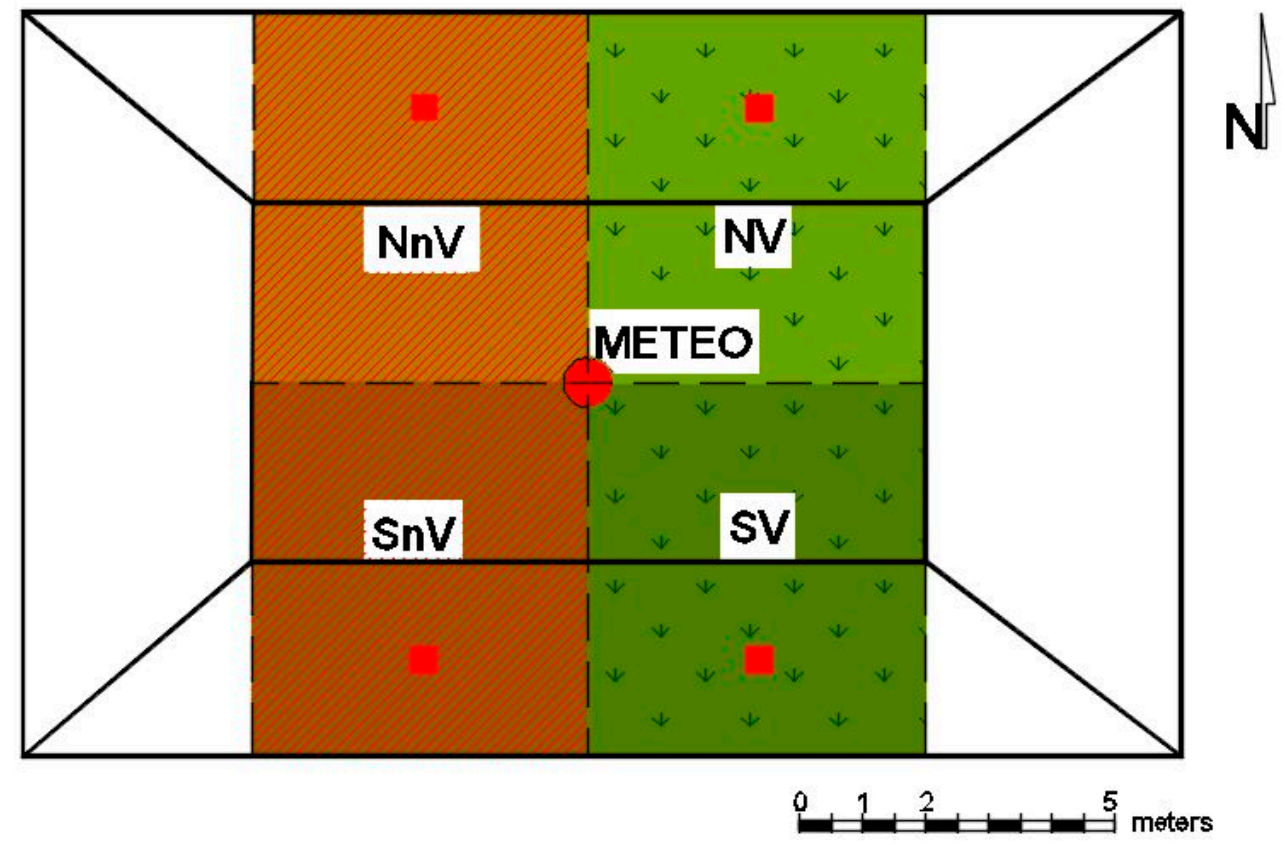

Figure 2. Schematic overview of the full-scale experiment divided into four partitions: SV, SnV, NV, and $\mathrm{NnV}$ (see text for explanations). The position of the four vertical sensor profiles (red squares) and the meteorological station (red dot) is illustrated. 


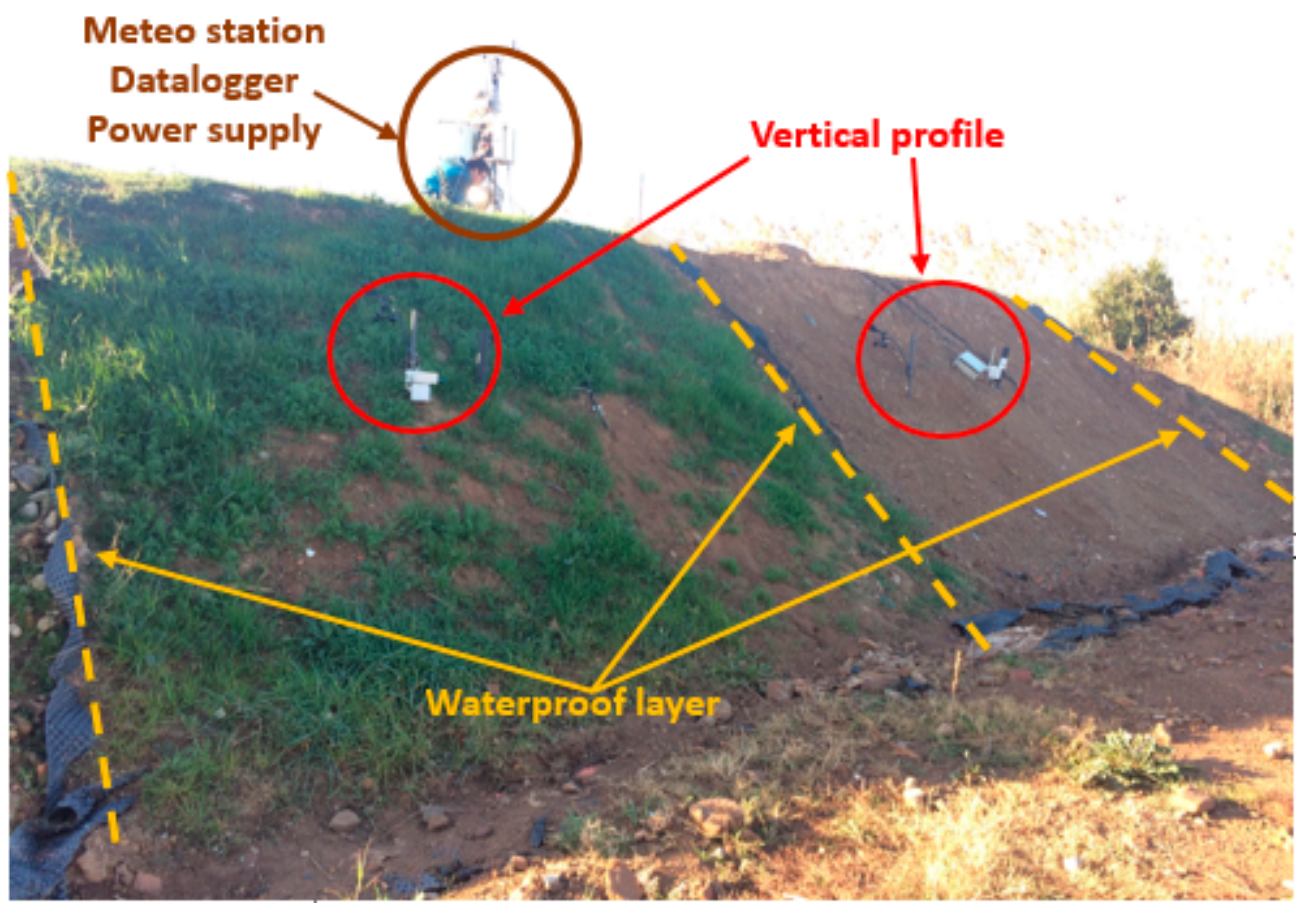

Figure 3. Photograph of the embankment after installation of the sensors looking towards the North slope.

\subsubsection{Vertical Sensor Profiles}

Each vertical profile measures air and soil temperature, relative humidity, barometric pressure, heat flux, pore water pressure (PWP), and volumetric water content (VWC) at different positions. A complete list of all the sensors and the recorded parameters is given in Table 1. Net solar radiation devices were installed at each of the orientations (North and South). The general distribution of the different devices is shown by the example of vertical profile $\mathrm{NnV}$ (Figure 4a). In addition, photographs of the soil texture format profiles $\mathrm{NnV}$ and $\mathrm{NV}$ during the sensors installation are shown in Figure $4 \mathrm{~b}, \mathrm{c}$ respectively. They show the sandy loamy soil with isolated gravel particles at both trenches, while the presence of organic material in the form of plant roots is visible in the vegetated North (NV) profile.

Table 1. Characteristics of the sensors installed in the vertical slope profiles.

\begin{tabular}{|c|c|c|}
\hline Parameter Measured & Model & Measuring Range \\
\hline Soil temperature & Campbell 107 & 35 to $+50^{\circ} \mathrm{C}$ \\
\hline Volumetric water content & \multirow{3}{*}{ Decagon 5TE } & 0 to $1 \mathrm{~m}^{3} / \mathrm{m}^{3}$ \\
\hline Soil temperature & & -40 to $+50^{\circ} \mathrm{C}$ \\
\hline Electric conductivity & & 0 to $23 \mathrm{dS} / \mathrm{m}$ \\
\hline $\begin{array}{l}\text { Pore water pressure } \\
\text { Soil temperature }\end{array}$ & Decagon MPS-6 & $\begin{array}{c}-9 \text { to }-100,000 \mathrm{kPa} \\
-40 \text { to }+60{ }^{\circ} \mathrm{C}\end{array}$ \\
\hline Pore water pressure & UMS T4 & -85 to $+100 \mathrm{kPa}$ \\
\hline Air temperature & \multirow{3}{*}{ Decagon VP-4 } & -40 to $+80^{\circ} \mathrm{C}$ \\
\hline Relative air humidity & & 0 to $100 \%$ \\
\hline Atmospheric pressure & & 49 to $109 \mathrm{kPa}$ \\
\hline $\begin{array}{c}\text { Wind speed } \\
\text { Wind direction }\end{array}$ & Davis Cup Anemometer & $\begin{array}{c}0.9 \text { to } 78 \mathrm{~m} / \mathrm{s} \\
0 \text { to } 360^{\circ}\end{array}$ \\
\hline Heat flux & Hukseflux HFP01 & $\pm 2000 \mathrm{~W} / \mathrm{m}^{2}$ \\
\hline Net solar radiation & Kipp \& Zonnen NR Lite2 & $\pm 2000 \mathrm{~W} / \mathrm{m}^{2}$ \\
\hline
\end{tabular}


Not each vertical profile has the distribution of sensors as shown in Figure $4 \mathrm{a}$ and the final number of devices installed in each profile ranges from 13 to 14 (Table 2). The parameter that is measured at most positions is temperature, which is monitored at least at 7 positions along each vertical profile, while PWP and VWC are registered at a minimum of 3 and 4 positions, respectively. The total number of records measured at all sensors for each of the non-vegetated slopes ( $\mathrm{SnV}$ and $\mathrm{NnV}$ ) and for each of the vegetated slopes (SV and NV) is 27 and 29, respectively. Some sensors had technical problems during the first year or were installed in the second phase. That's why the time series of specific sensors are not complete when presented in the results section.

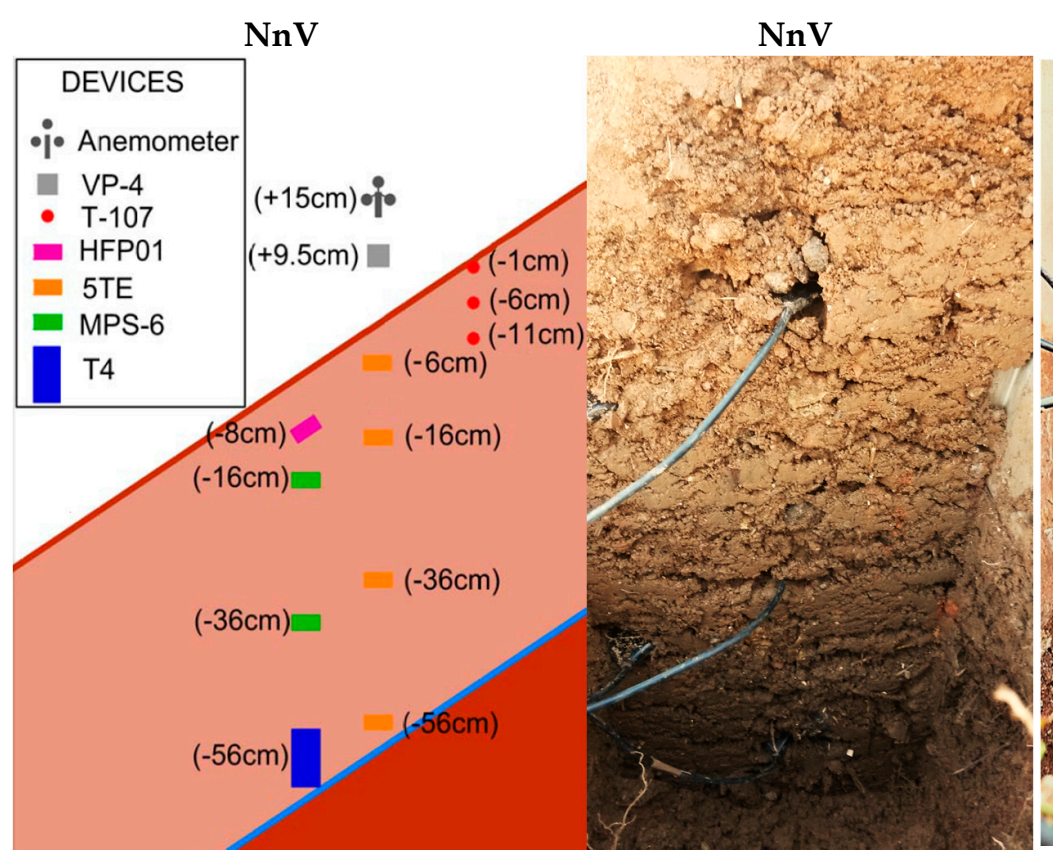

(a) (b)

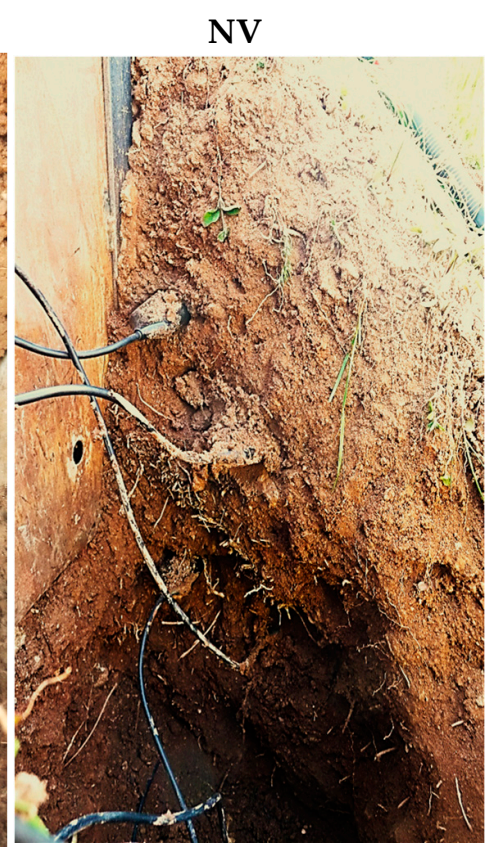

(c)

Figure 4. (a) Schematic design of the vertical profile of $\mathrm{NnV}$ indicating the location of the sensors; (b) photograph taken during installation of sensors at the $\mathrm{NnV}$ profile; (c) photograph taken during installation of sensors at the NV profile.

Table 2. Location of selected sensor in the four vertical profiles. Only devices focusing on temperature, volumetric water content, and pore water pressure are listed.

\begin{tabular}{ccccc}
\hline \multirow{2}{*}{ Sensor } & \multicolumn{4}{c}{ Depth of Installation (cm) } \\
\cline { 2 - 5 } & $\mathbf{S V}$ & $\mathbf{S n V}$ & $\mathbf{N V}$ & $\mathbf{N n V}$ \\
\hline \multirow{2}{*}{ Air/soil temperature } & $+9.5,-1,-6,-11$, & $+9.5,-1,-6,-11$, & $+9.5,-1,-6,-11$, & $+9.5,-1,-6,-11$, \\
Volumetric water content & $-16,-36,-43$ & $-16,-32,-36,-57$ & $-16,-36,-56$ & $-16,-36,-56$ \\
Pore water pressure & $-16,-36,-46,-43$ & $-6,-16,-36,-57$ & $-6,-16,-36,-56$ & $-6,-16,-36,-56$ \\
\hline
\end{tabular}

In the following, the different types of devices will be described and some characteristics discussed. In this study, two types of sensors are considered: (1) devices measuring temperature changes and heat flux along the atmosphere-soil interface, and (2) devices focusing on the infiltration of rainfall into the soil layer.

Air and soil temperature is measured at different positions close to the surface. In the most superficial part of the soil layer, three thermistors encapsulated in an aluminum housing (107, Campbell Scientific, Logan, UT, USA) were buried. The rest of the soil temperature is monitored by the thermistors incorporated in other sensors (MPS-6, Decagon Devices, Pullman, WA, USA, and 5TE, 
Decagon Devices, Pullman, WA, USA). Another sensor (VP-4, Decagon Devices, Pullman, WA, USA) measures the air temperature at $9.5 \mathrm{~cm}$ above the terrain surface.

The heat flux across a soil section is measured close and parallel to the surface, where most of the heat transfer is expected. For this reason, a thermopile (HFP01, Hukseflux, Delft, The Netherlands) is installed at $8 \mathrm{~cm}$ depth and transforms the measured voltage into heat flux. Finally, wind speed and direction is also registered at each vertical profile by a cup and vane anemometer installed $15 \mathrm{~cm}$ above the terrain surface.

Water content and pore water pressure are fundamental parameters to understand the atmosphere-vegetation-soil interactions related to rainfall infiltration into the soil. In the experiment, multiple devices register these processes in the vertical profiles, principally tensiometers and soil moisture sensors.

Two different types of tensiometers were installed for measuring pore water pressure: (i) porous ceramic disc tensiometers (MPS-6, Decagon Devices, Pullman, WA, USA), and (ii) porous ceramic cup tensiometer (T4, UMS, München, Germany). The MPS-6 dielectric water potential sensors are designed to measure suction values up to $100 \mathrm{MPa}$ and are located close to the surface (Table 2), where high suction values are expected. In contrast, the UMS T4 is a tensiometer that measures PWP in a negative and positive range. Thus, its installation is at the lower part of the monitored soil layer, where low suction or positive PWP values are expected. The UMS T4 device is a rather delicate sensor in comparison with the robust MPS-6. The UMS T4 tensiometers were refilled and calibrated in the laboratory before their installation. The refilling was made with de-aired water, ensuring no air bubbles remained inside the ceramic cup, which would lead to an incorrect pressure reading. In addition, the pressure measured by the transducer has to be corrected twice: (i) due to the elevation difference between the pressure transducer and the ceramic cup, and (ii) because of the different power excitation (our system supplies $12 \mathrm{~V}$, while the manufacturer calibration is performed at $10.6 \mathrm{~V}$ ). The installation of the UMS T4 tensiometers has to be carried out very carefully. To prevent surface runoff running down into the borehole along the tensiometer, a rubber water-retaining disk was slipped around the sensor at the soil surface and a perfect fit between the previously drilled hole and the device was performed.

The volumetric water content (VWC) is measured by Decagon 5TE sensors (Decagon Devices, Pullman, WA, USA), which are installed at different depths in the soil layer (Table 2). The 5TE uses an electromagnetic field to measure the dielectric permittivity of the surrounding medium. Prior to field installation, a calibration of the sensor was performed in the laboratory using soil samples with a similar bulk density as the embankment slope. The VWC that was recorded by the sensor was compared with the one determined by the standard procedure incorporating the void ratio, the gravimetric water content, and the specific gravity of the soil samples. The calibration results showed that there was no significance difference with the equation given by the manufacturer, therefore this equation was finally used for the transformation of the sensor reading into VWC.

\subsubsection{Meteorological Station}

The meteorological station consists of a standard tipping-bucket rain gauge with a resolution of $0.2 \mathrm{~mm}$ (ECRN-100, Decagon Devices, Pullman, WA, USA), a sensor which measures relative humidity, air temperature, vapor, and atmospheric pressure (VP-4, Decagon Devices, Pullman, WA, USA), a solar radiation sensor (Davis Vantage Pro2, Davis Instruments, Hayward, CA, USA), and a cup anemometer/wind vane, which measures wind direction and wind speed (Davis Cup Anemometer, Davis Instruments, Hayward, CA, USA). Details of the sensors installed at the meteorological station are listed in Table 3. In total, 8 different parameters are measured. 
Table 3. Sensors installed at the meteorological station.

\begin{tabular}{ccc}
\hline Parameter Measured & Model & Measurement Range \\
\hline Rainfall & Decagon ECRN-100 & $0.2 \mathrm{~mm}{ }^{*}$ \\
\hline Air temperature & & -40 to $+80{ }^{\circ} \mathrm{C}$ \\
Relative air humidity & Decagon VP-4 & 0 to $100 \%$ \\
Atmospheric pressure & & 49 to $109 \mathrm{kPa}$ \\
\hline Solar radiation & Davis Vantage Pro2 & 0 to $1800 \mathrm{~W} / \mathrm{m}^{2}$ \\
\hline Wind speed & Davis Cup Anemometer & 0.9 to $78 \mathrm{~m} / \mathrm{s}$ \\
Wind direction & 0 to $360^{\circ}$ \\
\hline
\end{tabular}

${ }^{*}$ Minimum resolution of sensor.

\section{Results}

\subsection{Laboratory Results}

The laboratory results from different soil samples of the material used for the construction of the embankment from the Llobregat river delta are summarized in Table 4.

Table 4. Soil properties of the material used for the construction of the embankment.

\begin{tabular}{cc}
\hline Soil Property & Value \\
\hline Gravel content $(\%)$ & $34-42$ \\
Sand content $(\%)$ & $30-43$ \\
Silt content $(\%)$ & $20-25$ \\
Clay content $(\%)$ & $4-6$ \\
Fines $(\%)$ & $25-31$ \\
Liquid limit (\%) & $29.5-34.4$ \\
Plastic limit $(\%)$ & $19.9-21.2$ \\
Plasticity index $(\%)$ & $9.7-13.5$ \\
Specific gravity $\left(\mathrm{Mg} / \mathrm{m}^{3}\right)$ & $2.65-2.70$ \\
Cohesion $(\mathrm{kPa})$ & 0 \\
Friction angle $\left({ }^{\circ}\right)$ & 58 \\
Hydraulic conductivity $(\mathrm{m} / \mathrm{s})$ & $7.7 \times 10^{-8}-1.8 \times 10^{-7}$ \\
\hline
\end{tabular}

Table 5 lists a summary of the most important parameters determined from undisturbed soil samples. Differences in density between the North and South slopes may be due to the compaction process during the construction.

Table 5. Soil properties of materials sampled after construction of the embankment at the two monitored slopes (South and North).

\begin{tabular}{ccc}
\hline Soil Property & South Slope & North Slope \\
\hline Bulk density $\left(\mathrm{Mg} / \mathrm{m}^{3}\right)$ & $1.72-1.78$ & $1.85-1.93$ \\
Dry density $\left(\mathrm{Mg} / \mathrm{m}^{3}\right)$ & $1.52-1.57$ & $1.55-1.61$ \\
Water content $(\%)$ & $13.23-15.11$ & $19.08-19.84$ \\
Void ratio $(-)$ & $0.70-0.76$ & $0.66-0.72$ \\
Porosity (-) & $0.41-0.43$ & $0.40-0.42$ \\
\hline
\end{tabular}

\subsubsection{Basic Soil Characterization}

First, the grain-size distribution was determined for two samples. The resulting curves show some minor differences (Figure 5) and the values are listed in Table 4. According to the Unified Soil Classification System (USCS) the soils can be classified as SC (clayey sand) including a large part of coarse-grained particles. The Atterberg limits indicate that the fine-grained part has a low plasticity 
behavior (Table 4). This low plasticity index indicates that small changes in soil humidity involve important changes of its consistency.

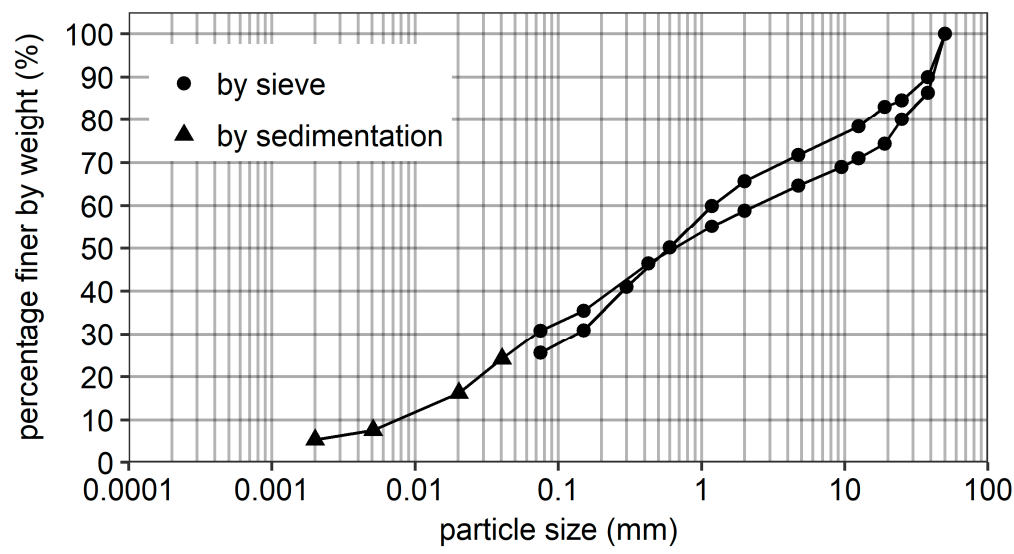

Figure 5. Particle-size distribution of the material used for the construction of the monitored embankment.

\subsubsection{Strength Parameters}

Figure 6 shows the results of three soil samples sheared with a normal stress of $21 \mathrm{kPa}$ under partially and saturated conditions. Samples under partially saturated conditions presented a clear peak shear strength and a dilatant behavior. This is a typical behavior of over-consolidated soils [45]. In contrast, saturated samples showed a contractive behavior with no clear peak. This behavior indicates that the saturation process induces a reduction in the apparent preconsolidation pressure of soil [46].
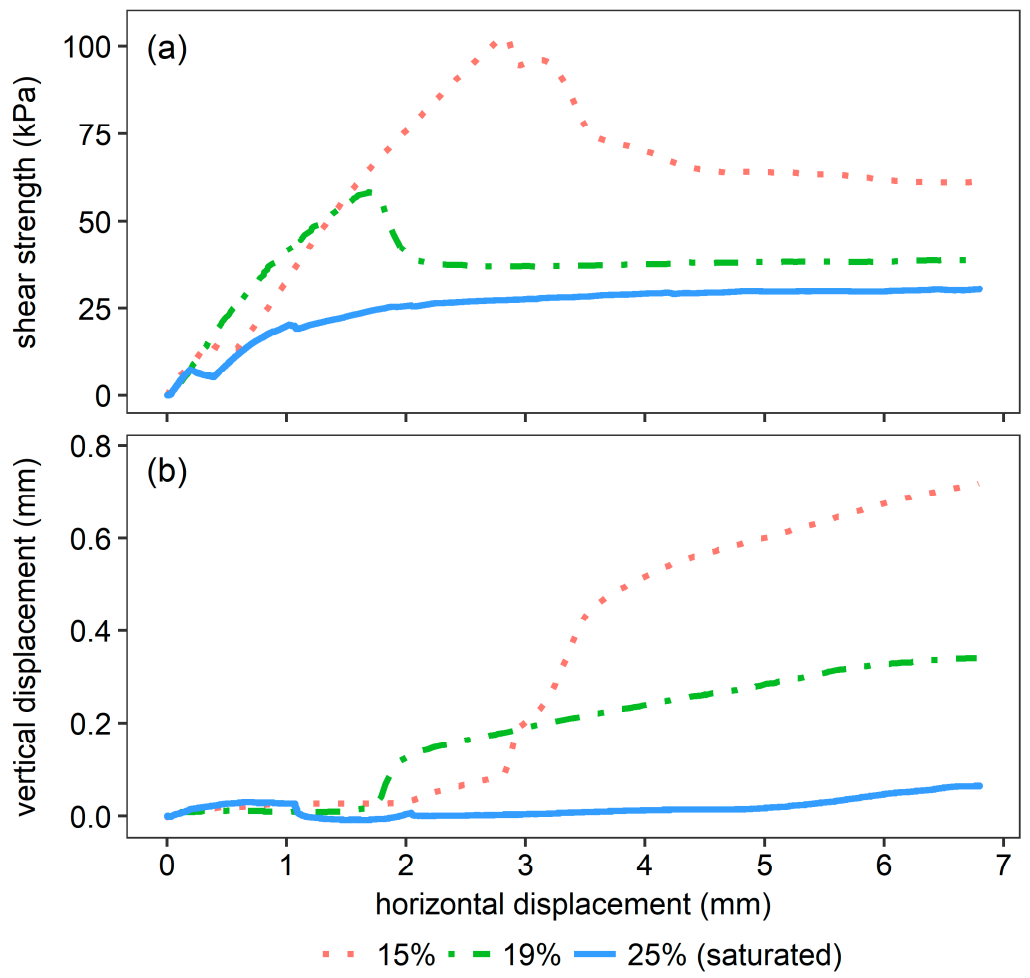

Figure 6. Results of three direct shear tests performed on partially and completely saturated samples applying a normal stress of $21 \mathrm{kPa}$. (a) Shear strength versus horizontal displacement; (b) Vertical displacement versus horizontal displacement. 
The normal versus shear stress relation of all tests are plotted in Figure 7. Results confirm the importance of water content in the soil, when strength parameters are analyzed. In particular, the great contribution of suction to the shear strength must be taken into account. The data of the direct shear test also shows that peak shear stress decreases and gets closer to constant volume shear stress when the sample is closer to saturated conditions. For unsaturated soils, the intergranular stress may be defined as [47]:

$$
\sigma_{n}^{\prime}=\sigma_{n}+\chi \cdot s=\sigma_{n}+S_{r} \cdot s,
$$

where $\sigma_{n}^{\prime}$ is the Bishop's generalized normal effective stress for unsaturated soils, $\sigma_{n}$ is the normal stress, $\chi$ is the Bishop's parameter and $s$ is suction. Bishop's parameter $\chi$ is a function of the saturation degree $S_{r}$ and is imposed to vary between 0 for dry soils to 1 for saturated soils which can be roughly assumed to have the value of the saturation degree [48].

In addition, the shear strength of unsaturated soils can be defined in terms of two independent stress variables, the normal stress and suction [49]:

$$
\tau=c^{\prime}+\sigma_{n} \tan \phi^{\prime}+s \tan \phi^{b},
$$

where $\tau$ is the shear strength, $c^{\prime}$ the effective cohesion, $\sigma_{n}$ the normal stress, $s$ is suction, $\phi^{\prime}$ the effective friction angle and $\phi^{b}$ represents the frictional contribution by suction to shear strength. Replacing Bishop's generalized effective stress for unsaturated soils in Equation (1) with Fredlund's unsaturated shear strength of Equation (2) and considering $\chi=S_{r}$, the following expression is obtained:

$$
\tau=c^{\prime}+\sigma_{n} \tan \phi^{\prime}+s S_{r} \tan \phi^{\prime}=c^{\prime}+\sigma_{n} \tan \phi^{\prime}+s \tan \phi^{b}
$$

from which can be deduced that:

$$
\tan \phi^{b}=S_{r} \tan \phi^{\prime}
$$
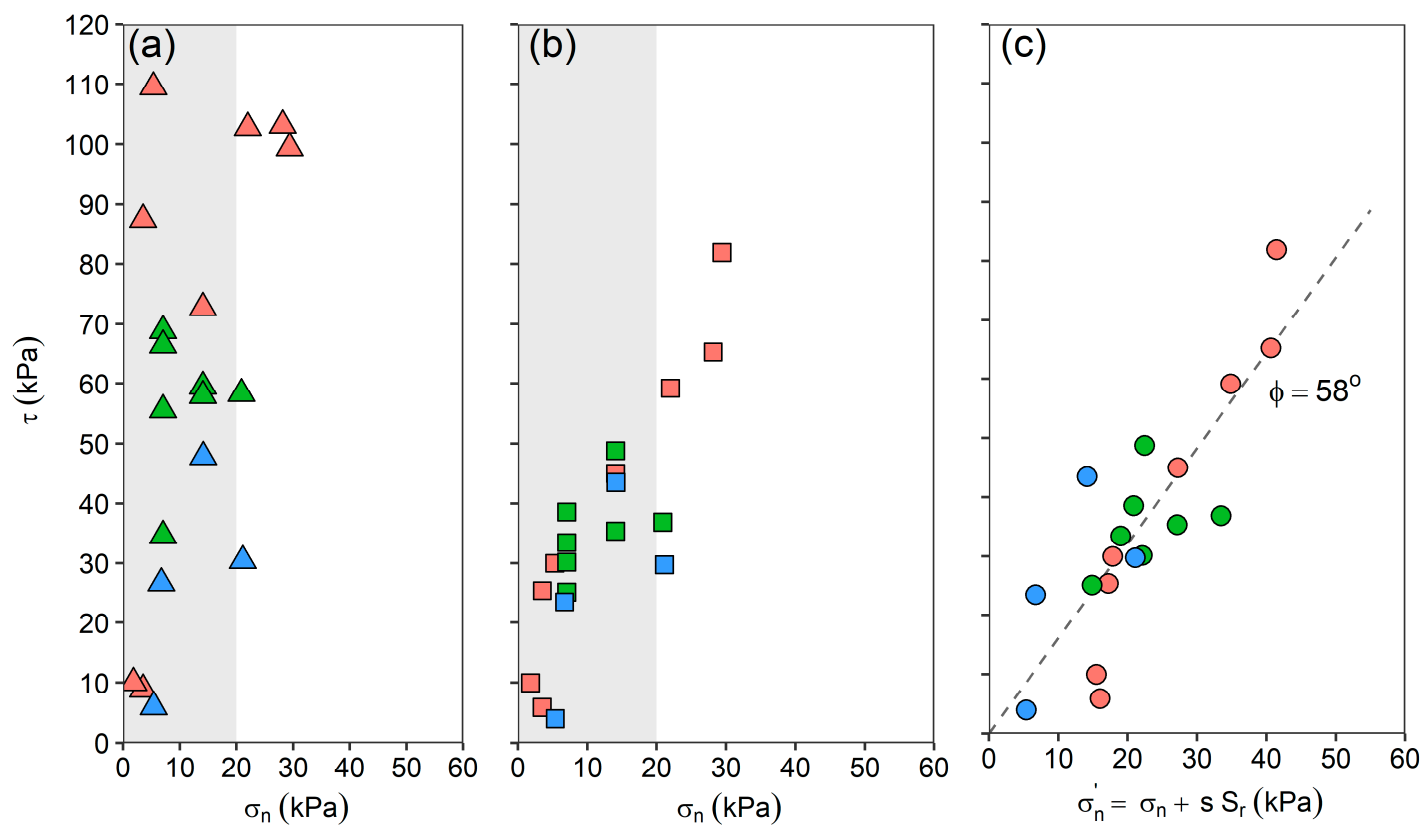

water content $\square 15 \% \square 19 \% \square 25 \%$ (saturated)

Figure 7. Results of direct shear tests performed on partially and completely saturated samples. (a) Normal stress versus peak shear stress; (b) normal stress versus constant volume shear stress; (c) Bishop's generalized effective normal stress versus constant volume shear stress. Shaded grey area represents the range of normal stresses expected on the monitored soil layer. 
The resulting failure envelope using Bishop's generalized effective stress for partially saturated soils at constant volume shear strength is defined by a friction angle of $58^{\circ}$ and zero cohesion (Figure $7 \mathrm{c}$ ). This high friction angle is the result of the low normal stress up to $30 \mathrm{kPa}$ applied to the samples. For higher normal stress values, a lower friction angle and a non-linear failure envelope are expected [50].

\subsubsection{Hydraulic Behavior}

The permeability ranges over almost four orders of magnitude (Figure 8 ), while values are between $7.7 \times 10^{-8}$ and $1.8 \times 10^{-7} \mathrm{~m} / \mathrm{s}$ regarding void ratios observed in the embankment $(0.66-0.76)$. However, in situ infiltration tests must be performed to finally determine the permeability, since field hydraulic conductivity may be much higher than the one achieved in the laboratory [42].

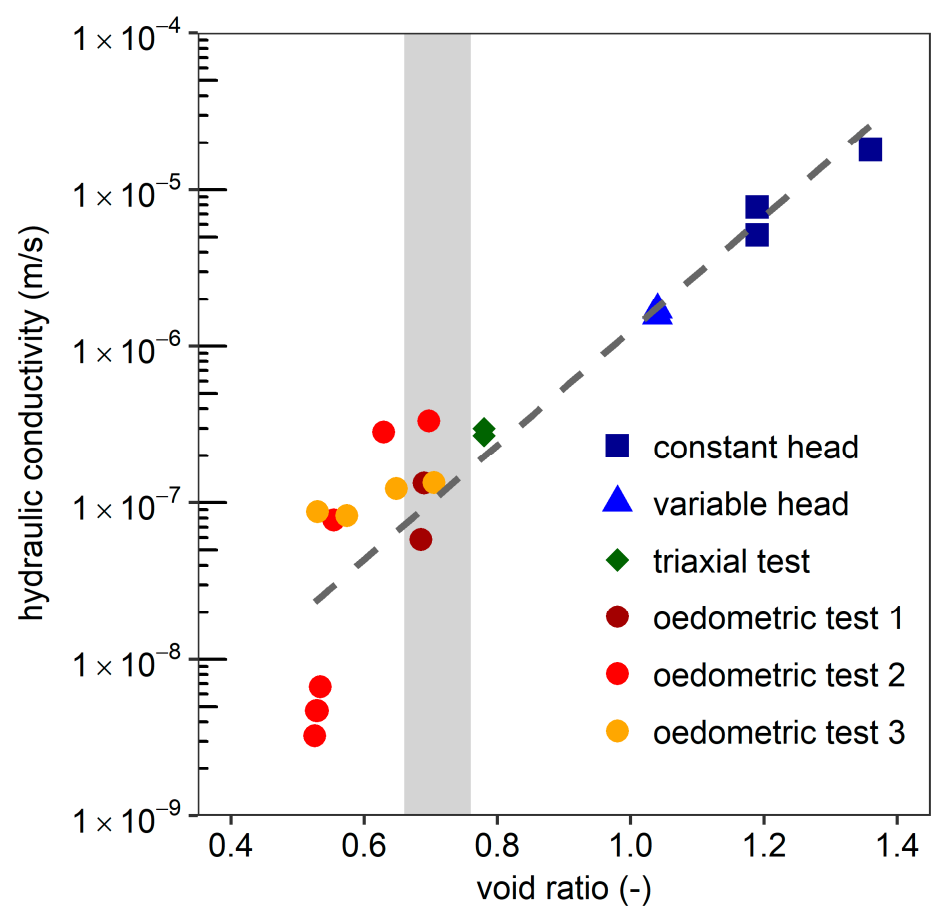

Figure 8. Saturated hydraulic conductivity for different void ratios obtained by different laboratory tests. Dashed line shows the best-fit relation. Grey shaded area represents the expected void ratio in the embankment.

In addition, an experiment was performed using a column with a diameter of $14.3 \mathrm{~cm}$ and a height of $35 \mathrm{~cm}$, filled with a soil dry density of $1.52 \mathrm{Mg} / \mathrm{m}^{3}$. A laboratory and field ceramic cup tensiometer (UMS T5x and UMS T4) and a dielectric water potential sensor (Decagon MPS-6) were installed in the column in order to measure suction and a capacitance moisture probe (Decagon 5TE) was used to measure volumetric water content. This soil column experiment provided supplementary data using a slightly smaller dry density sample. Initially, the sample was fully saturated, and it dried out progressively with time.

An extra experiment was performed on samples with a dry density of $1.39 \mathrm{Mg} / \mathrm{m}^{3}$, using a dielectric water potential sensor (Decagon MPS-6) to measure suction and a capacitance moisture probe (Decagon 5TE) to measure volumetric water content. This experiment was performed without following a specific drying-wetting path, measuring the suction on statically compacted samples with different water contents. An important aspect is that all these experiments helped to check the handling and accuracy of the sensors that later were placed at the embankment.

The data measured by the different methods allowed defining the wetting and drying SWRCs (Figure 9). The suction readings obtained by T5x sensor during the soil column experiment were not 
represented, since they were identical to those measured by sensor T4. A modified van Genuchten model that is more suitable for high suction values was applied. It can be expressed as [51]:

$$
S_{e}=\frac{S_{r}-S_{r l}}{S_{l s}-S_{r l}}=\left(1+\left(\frac{S}{P}\right)^{\frac{1}{1-\lambda}}\right)^{-\lambda}\left(1-\frac{s}{P_{s}}\right)^{\lambda_{s}},
$$

where $S_{e}$ is the effective degree of saturation, $S_{r}$ is the current saturation degree, $S_{l s}$ and $S_{r l}$ are the maximum and residual degree of saturation respectively, $s$ is suction, and $P$ and $\lambda$ are the van Genuchten material parameters. $\lambda_{S}$ and $P_{S}$ are the modified van Genuchten material parameters, which reduce high suction values, $P_{S}$ is the maximum suction at the minimum degree of saturation. The resulting modified van Genuchten fitted parameters for both drying and wetting paths are summarized in Table 6.

Table 6. Modified van Genuchten soil-water retention curve (SWRC) fitting parameters for drying-wetting paths.

\begin{tabular}{ccc}
\hline Fitted Parameters & Drying & Wetting \\
\hline$P(\mathrm{kPa})$ & 66.7 & 9.5 \\
$\lambda(-)$ & 0.28 & 0.20 \\
$P_{S}(\mathrm{kPa})$ & $2.5 \times 10^{5}$ & $2.5 \times 10^{5}$ \\
$\lambda_{S}(-)$ & 1.30 & 2.80 \\
$S_{l s}$ & 1 & 1 \\
$S_{r l}$ & 0 & 0 \\
\hline
\end{tabular}

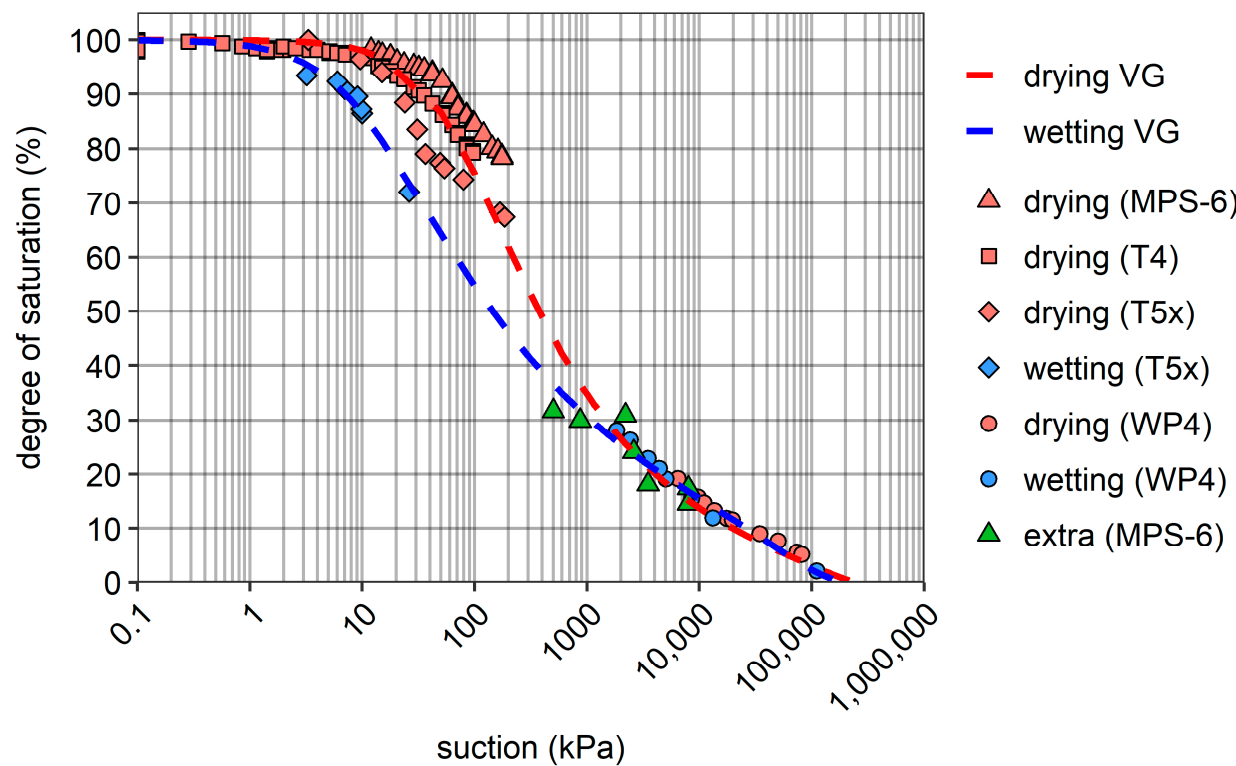

Figure 9. SWRC obtained by laboratory tests using different sensors. The resulting curves were calculated for drying-wetting conditions applying the modified van Genuchten (VG) model.

\subsection{Monitoring Results}

In this section, the data measured during the first year are presented and discussed. Emphasis has been given on the complete time series registered by the sensors installed at the bare slopes ( $\mathrm{NnV}$ and $\mathrm{SnV}$ ). The time series cover the period of almost one year between April 2017 and the end of March 2018. Data measured at the two vegetated slopes are not presented, because on one side, there is no complete time series and on the other side, the vegetation is not fully developed. Data loss between the 7th and the 22th of September occurred due to technical problems. 


\subsubsection{Temperature Data}

Time series of temperature measurements at different depths from the North bare slope are compared with the ones of the South bare slope together with daily rainfall (Figure 10). A clear difference is appreciated between the North and South slopes and a generally higher temperature is recorded on the South slope. In addition, the sensors, which are installed close to the ground surface, indicate larger daily fluctuations at the South slope. These daily fluctuations decrease with depth and no prominent variations can be observed at $-56 \mathrm{~cm}$ between the two slopes. During spring and summer, temperature measurements at the deepest sensors (at -56 and $-57 \mathrm{~cm}$ ) are closer to the lower bound of the daily fluctuations of the most surficial sensors (at -1 and $-16 \mathrm{~cm}$ ), while in autumn and especially in winter, these measurements are closer to the upper bound. This characteristic is more noticeable on the North-facing slope, where soil temperatures at $-56 \mathrm{~cm}$ sometimes are higher than the temperature at ground surface $(-1 \mathrm{~cm})$. This effect is due to the minor atmosphere interaction on the deepest soil layer, at $-56 \mathrm{~cm}$, and due the high thermal capacity of the soil to retain the heat transferred by radiation during spring and summer by the shallower layers. Soil temperature is mostly affected by climate interaction determined by air temperature, solar radiation, air humidity, rainfall, and wind, but also due to the ground surface cover (bare ground, vegetated slopes, etc.) and soil structure and physical properties [52].

The effect of rainfall on the soil temperature is of minor influence when looking at the complete time series, but some individual temporal decreases of temperature close to the surface can be observed. An example of these specific rainfall episodes, which affect the temperature measurements, is illustrated in continuation.
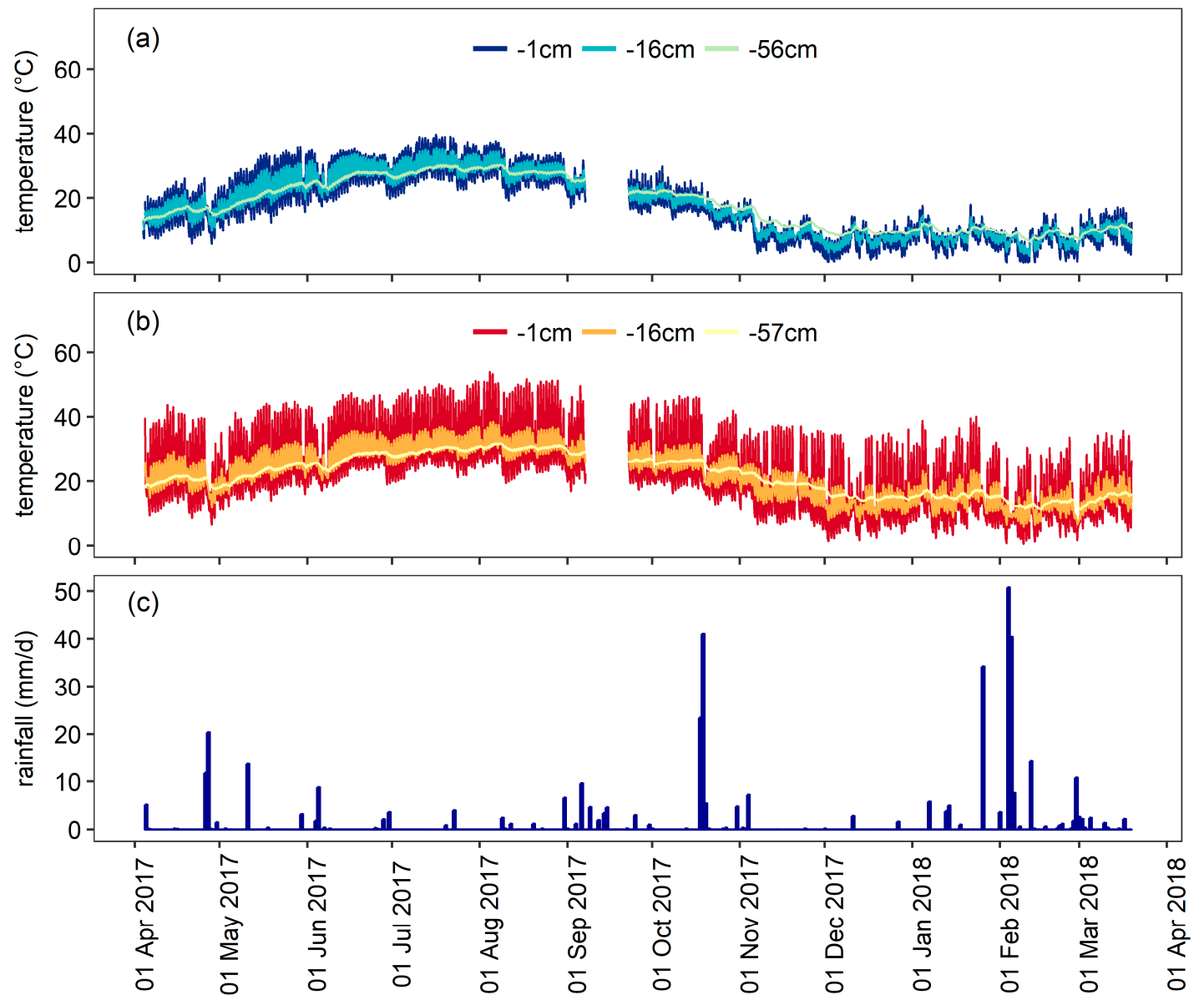

Figure 10. Soil temperature of the complete time series registered at the full-scale experiment. (a) North slope without vegetation; (b) South slope without vegetation; (c) daily rainfall. 
The effects of an individual rainfall episode that occurred at the end of April 2017 are shown in Figure 11. The measured data indicate a strong relation between the rainfall and both the air and soil temperatures. While the daily temperature fluctuations are clearly visible before and after the rainfall episode at most sensors, temperature records contain a smoothening and slight general decrease during the rainfall, probably due to solar radiation reduction during rainy periods. Another interesting fact is that at the south slope the soil temperature at shallow depths are due to solar radiation much higher than the air temperature during sunny days. It can also be observed that the maximum or minimum peaks of the soil temperature occur later than the air temperature peak values, with an increasing of the lag effect with depth. This effect is detected at both slopes, but is much more intense in the South profile. In addition, soil temperature during the event is slightly higher than air temperature measured at $9.5 \mathrm{~cm}$ over the soil surface.
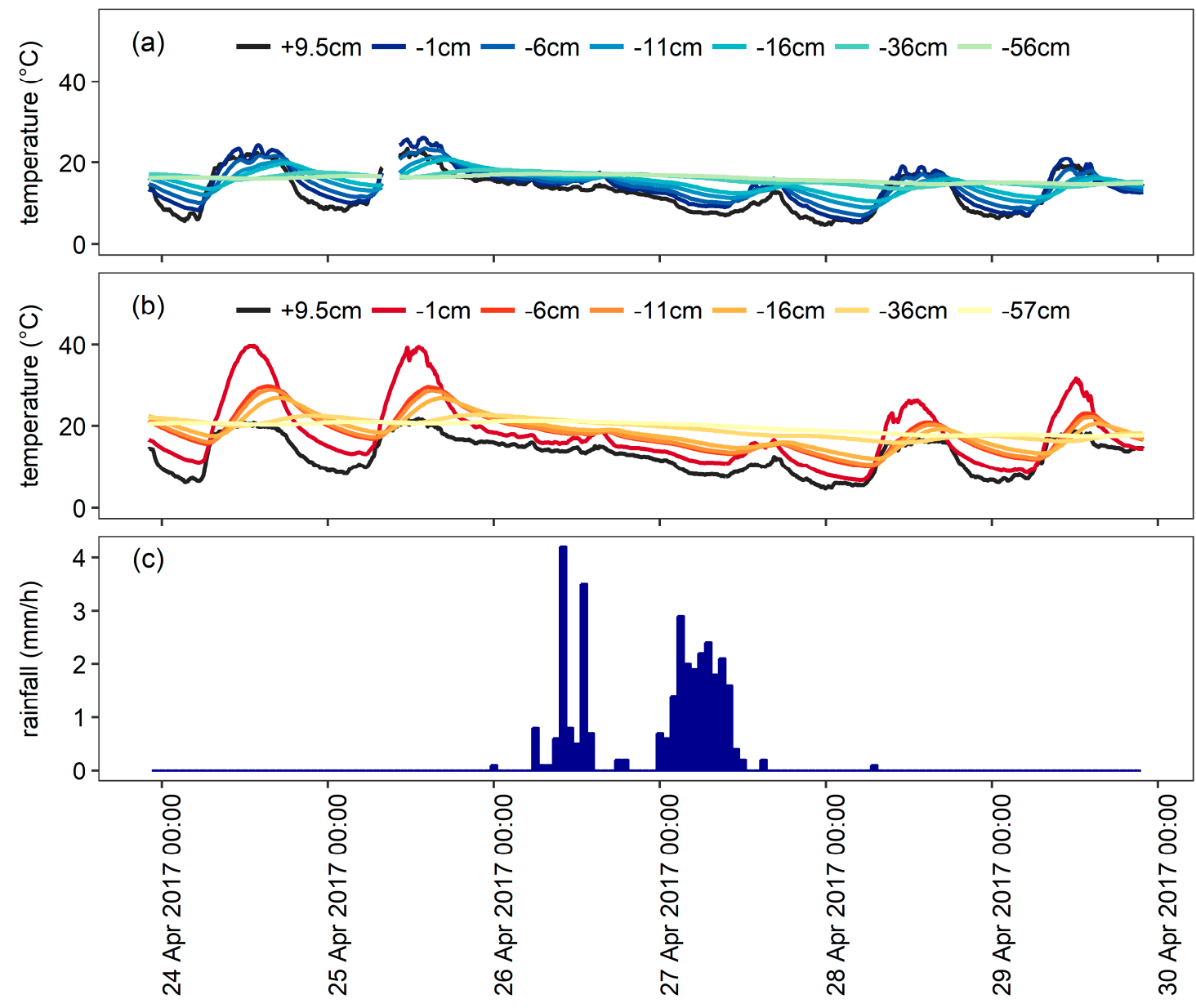

Figure 11. Air and soil temperature registered at the North $(\mathrm{N})$ and South $(\mathrm{S})$ slopes without vegetation during a rainstorm in April 2017. (a) Temperature data at the North slope; (b) temperature data at the South slope; (c) hourly rainfall.

\subsubsection{Hydrologic Slope Response}

Slope response to rainfall infiltration and its interaction with the atmosphere was evaluated through the changes in PWP and VWC. Time series of VWC and PWP measurements at three different depths at the North and South bare slopes are compared with the corresponding daily rainfall (Figure 12). Two well-known trends can be observed: (i) infiltration due to rainfall increases VWC and PWP and therefore reduces suction in partially saturated conditions, and, (ii) time intervals with less rainfall decreases VWC and PWP and thus increase suction. In addition, the measurements show that the soil close to the surface is strongly influenced by rainfall and evaporation, while this 
effect decreases with depth. The relation between rainfall and both VWC and PWP is confirmed by sharp increases at the shallow sensors (at $-16 \mathrm{~cm}$ and with minor magnitude at $-36 \mathrm{~cm}$ ) and at both slopes. The rainfall episodes with clearest VWC and PWP response occurred on 26-27 April 2017, 18-19 October 2017, 26 January 2018, and 4-5 February 2018. A comparison of the two slopes shows that the North slope is generally characterized by slightly higher soil moisture than the South slope.

Regarding the entire time series, the highest VWC values and reduced suction were recorded just after the installation of the sensors for approximately two months (April and May 2017). Following this period, the most important drying phase occurred, which took place during the month of June with a suction increase of $\sim 36-60 \mathrm{kPa}$ /day for the shallower sensors $(-11$ and $-16 \mathrm{~cm}$ respectively), $\sim 31-48 \mathrm{kPa} /$ day for the middle sensors ( -32 and $-36 \mathrm{~cm}$ respectively), and $\sim 3-4 \mathrm{kPa} /$ day for the deepest sensors ( -72 and $-62 \mathrm{~cm}$ respectively). In the following months (July-mid October), a smooth decrease in both VWC and PWP was recorded. This trend breaks with an extreme rainfall episode recorded on the 18th and 19th of October 2017, when $64 \mathrm{~mm}$ rainfall over $24 \mathrm{~h}$ were measured. This rainfall provoked a sharp and important increase at the shallow sensors of both slopes. The increase in VWC and PWP is less important with soil depth and has no prominent variation at the deepest soil moisture sensors (located at -56 and $-57 \mathrm{~cm}$ respectively). After this heavy and long duration rainfall, the shallow soil layer down to $16 \mathrm{~cm}$ depth was near to saturation for both slopes, since the suction measurements were close to $0 \mathrm{kPa}$. The VWC registered very high values at the south slope, while the same sensor at $-16 \mathrm{~cm}$ at the North slope exhibited technical problems with some data lost. Nevertheless, it can be deduced from the readings recorded during the month of November that the VWC increase was also important. Two rainfall events at the beginning of 2018 triggered an important increase in water content and pore water pressure. One on the 26th of January with $34 \mathrm{~mm}$ rain in $24 \mathrm{~h}$, and the highest rainfall recorded during the entire study, which occurred on the 4th and 5th of February 2018 and included $90 \mathrm{~mm}$ rain in $30 \mathrm{~h}$. After these two rainfall episodes, VWC and PWP values strongly increased and continued at high values with only a slight decreasing trend.

In the following, special attention is given to the pore water pressure measurements gathered by the T4 ceramic cup tensiometers (Figure 12c). These tensiometers are the most delicate devices in the monitoring set-up, because the water-filled cup starts to de-saturate when the soil gets dryer than $\sim 90 \mathrm{kPa}$ suction. In this case, it needs to be uninstalled in the field and saturated again in the laboratory with de-aired water. The initial T4-readings show a similar behavior as the ones recorded by the MPS-6 dielectric water potential sensors (Figure 12b): very low suction values close to saturation during the first 2 months. After the high drying rate of June, the North tensiometer, at $62 \mathrm{~cm}$ depth, reached its maximum suction value of about $85 \mathrm{kPa}$ and remained constant for several days. Then, the measures changed abruptly to $0 \mathrm{kPa}$. The interpretation of this sharp change is that the soil at that depth got even dryer at that moment, reaching the ceramic bubble point of $1500 \mathrm{kPa}$. Consequently, the cup, which is filled with de-aired water, quickly ran out and was fully filled with air. Therefore, the tensiometer was extracted on the 20th of September and saturated with de-aired water in the laboratory, reinstalling it on the 5 th of October. The measurements after reinstalling the North tensiometer reached its maximum suction value of $85 \mathrm{kPa}$ in $36 \mathrm{~h}$, indicating suction at that depth was higher than $85 \mathrm{kPa}$, partially de-saturating the ceramic cup. This reading remained almost constant for two weeks until a heavy and long duration rainfall on the 18th and 19th of October saturated the ceramic cup and its readings reached the value of $4 \mathrm{kPa}$ suction over $24 \mathrm{~h}$. In contrast, the South T4 tensiometer did not reach its maximum suction value of $85 \mathrm{kPa}$ during the month of June and suction values were slightly decreasing from August $2017(\sim 30 \mathrm{kPa})$ until February $2018(\sim 17 \mathrm{kPa})$. Then, the very important rainfall event on the 4th and 5th of February 2018 produced a sharp change. After this heavy rainfall, readings at the North and South tensiometers indicate a complete saturation at that depth $(0.85 \mathrm{kPa}$ and $1.13 \mathrm{kPa}$ ). These PWP values represent a water column of $8.7 \mathrm{~cm}$ and $11.6 \mathrm{~cm}$ above the sensors at the North and South slope, respectively. 

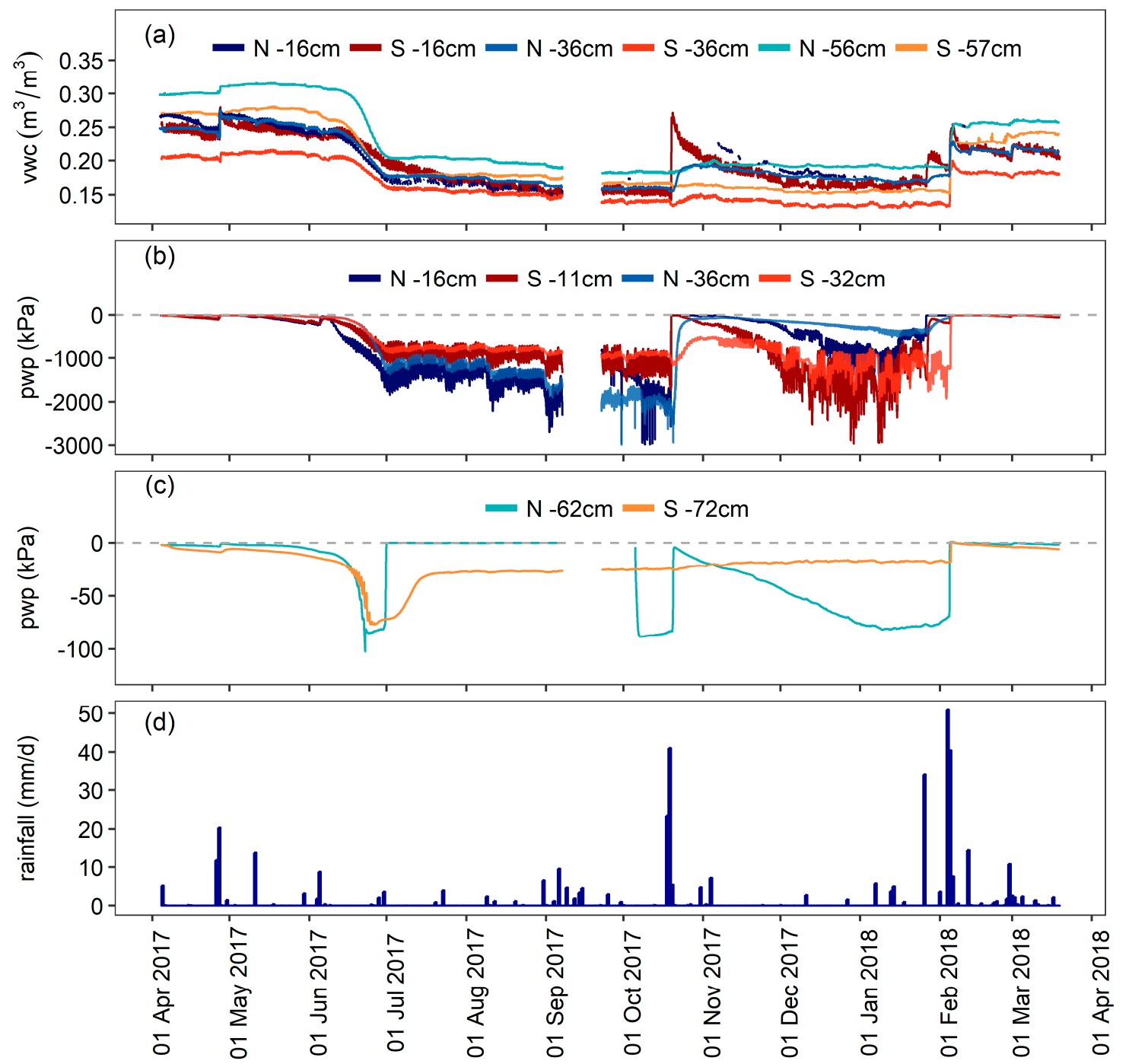

Figure 12. Rainfall infiltration at the North $(\mathrm{N})$ and South $(\mathrm{S})$ slope without vegetation. (a) Volumetric water content data measured by 5TE; (b) pore water pressure recorded by MPS- 6 tensiometers; (c) pore water pressure measured by $\mathrm{T} 4$ tensiometers; (d) daily rainfall.

Many rainfalls have been recorded throughout the recorded period, but most of them did not trigger a significant change in moisture and pore water pressure. These results suggest that part of the rainfall did not infiltrate, but transformed into surface runoff. That's why the ratio between infiltration and surface runoff is closely related to the duration and intensity of rainfall, as well as the initial conditions of soil moisture and the slope angles, amongst others [53]. In the following, two examples of the time series are selected: (i) a "long duration" rainfall that generated important changes in terms of moisture and pore water pressure (Figure 13), and, (ii) a "short duration" rainfall that lasted $3 \mathrm{~h}$ and did not trigger significant variations (Figure 14).

The "long duration" rainfall episode lasted $\sim 35 \mathrm{~h}$, accumulated a total amount of $32 \mathrm{~mm}$, and therefore had an average rainfall rate of $0.9 \mathrm{~mm} / \mathrm{h}$. The effect of rainfall on moisture and pore water pressure shows a direct relation between the rainfall timing and the infiltration process (Figure 13). There is a clear time lag that increases with depth, indicating a vertical flow trajectory. The magnitude of moisture and pore water pressure changes decreases with depth and has negligible variations at the deepest soil moisture sensors (at -56 and $-57 \mathrm{~cm}$, respectively). Both MPS- 6 and T4 tensiometers finally reached values close to $0 \mathrm{kPa}(9 \mathrm{kPa}$ is the minimum suction range for MPS-6 device), which indicated that the soil was close to saturation after this rainfall episode. 

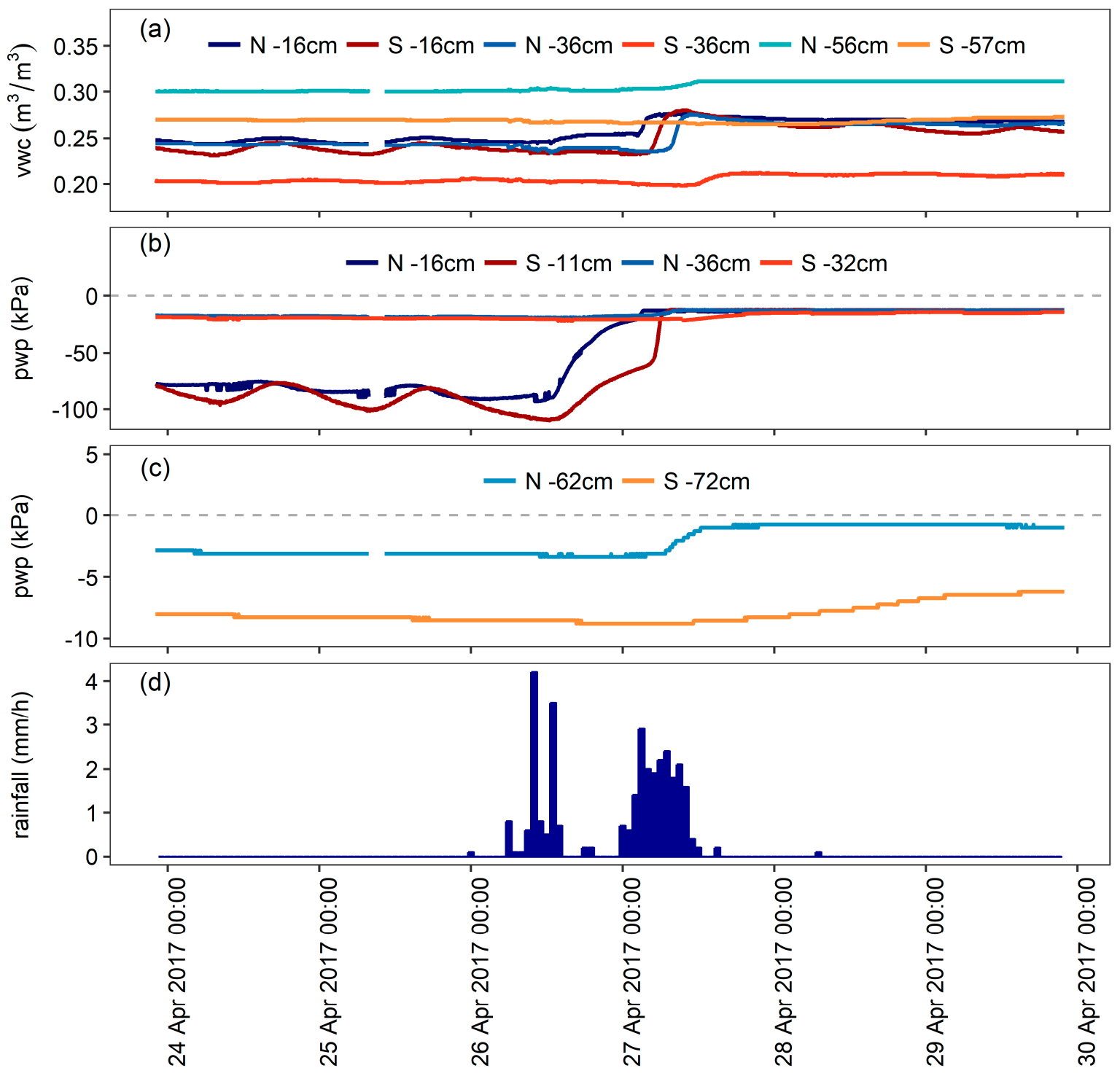

Figure 13. Soil moisture and pore water pressure registered during a rainstorm in April 2017 at the North (N) and South (S) slopes without vegetation. (a) Volumetric water content data measured by $5 \mathrm{TE}$; (b) pore water pressure recorded by MPS-6 tensiometers; (c) pore water pressure measured by T4 tensiometers; (d) hourly rainfall.

The "short duration" rainfall lasted only three hours, accumulated a total amount of $13.8 \mathrm{~mm}$, and had a clear hourly peak with an intensity of $12.7 \mathrm{~mm} / \mathrm{h}$. There is no response on the volumetric water content sensors at all depths, while pore water pressure slightly increase on the most superficial sensors located at $16 \mathrm{~cm}$ depth (Figure 14). This suggests a clear relationship between rainfall duration and intensity and the subsequent infiltration process. Therefore, a runoff measurement system will be installed in 2018 at each of the four monitored slopes in order to understand better the rainfall infiltration and runoff process and to corroborate the infiltration rate. 

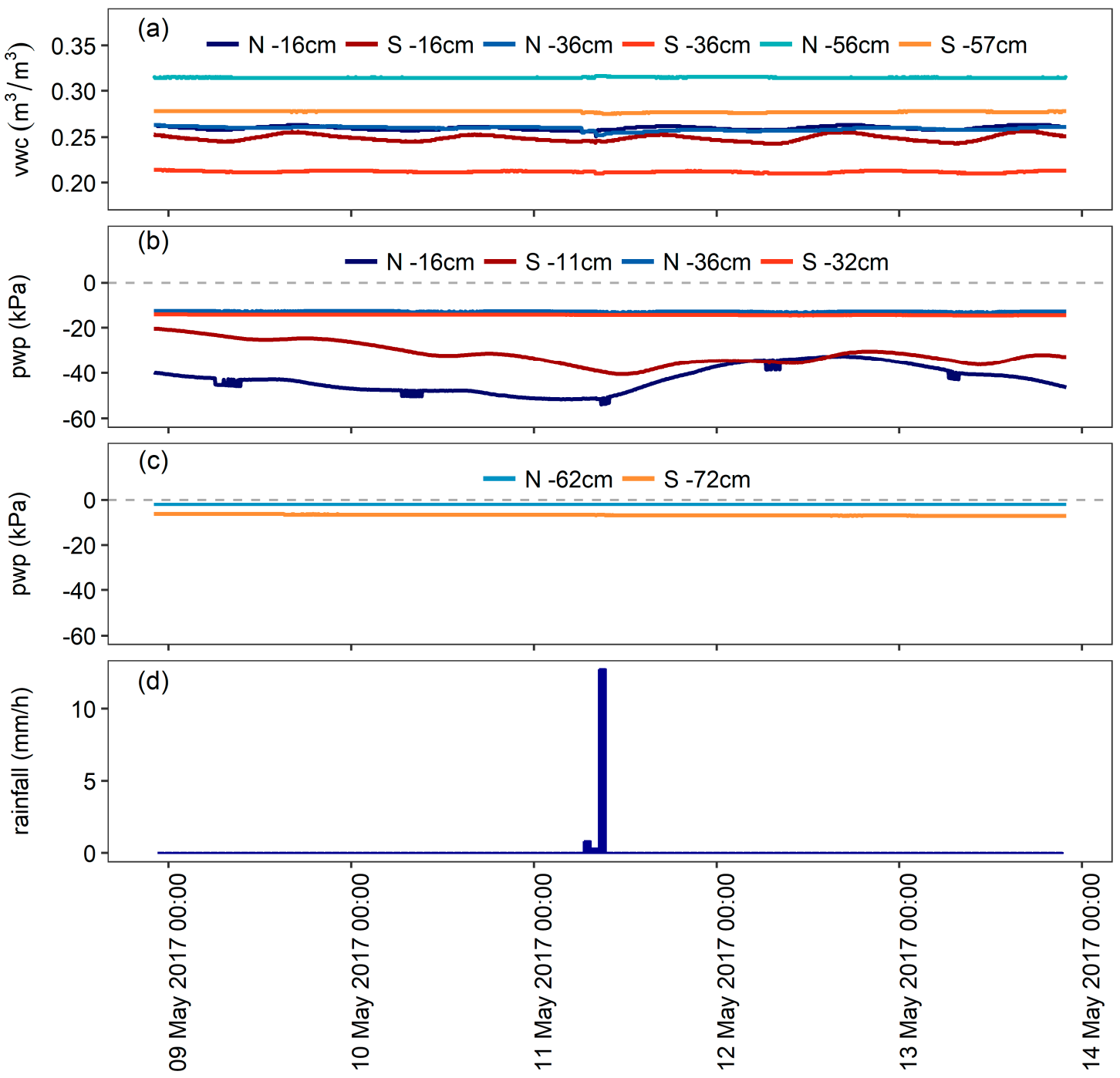

Figure 14. Soil moisture and pore water pressure registered during a rainstorm in May 2017 at the North (N) and South (S) slopes without vegetation. (a) Volumetric water content data measured by 5TE; (b) pore water pressure recorded by MPS-6 tensiometers; (c) pore water pressure measured by T4 tensiometers; (d) hourly rainfall.

Finally, the temporal variation of VWC, PWP, and soil-air temperature with depth is illustrated for both North and South bare slopes during the first year of monitoring in two-month intervals (Figure 15). The data show that the South slope is somewhat dryer in terms of VWC, with the lowest VWC values at $36 \mathrm{~cm}$ depth for almost all the recorded period. Changes in PWP are more important on the shallower devices while there are no important variations on the deepest ones. There are no PWP readings at $-62 \mathrm{~cm}$ during the months of August and October 2017 because of the desaturation of the North T4 tensiometer. In terms of soil temperature, a clear difference is appreciated between the North and South slopes with higher values on the South-facing slope. This difference in temperature is much more noticeable at the most surficial sensor, at $1 \mathrm{~cm}$ depth, with temperatures up to $40{ }^{\circ} \mathrm{C}$ due to solar radiation. In contrast, the radiation effect is not appreciated on the North-facing slope. This radiation effect strongly decreases with depth and only a minor influence is observed at $6 \mathrm{~cm}$ depth. On the South-facing slope, temperature differences of about $10{ }^{\circ} \mathrm{C}$ between the sensors at $-1 \mathrm{~cm}$ and $-6 \mathrm{~cm}$ are observed for most months.

The higher VWC values measured at intermediate depth could be explained by taking into account differences in the porosity of the soil surrounding the sensors. 
(a)

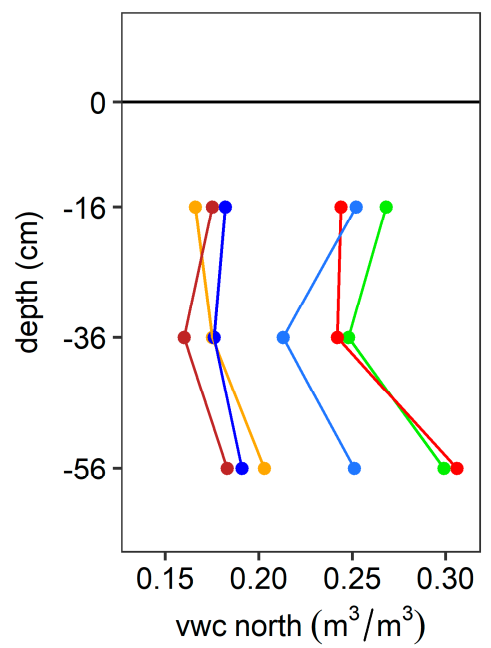

(d)

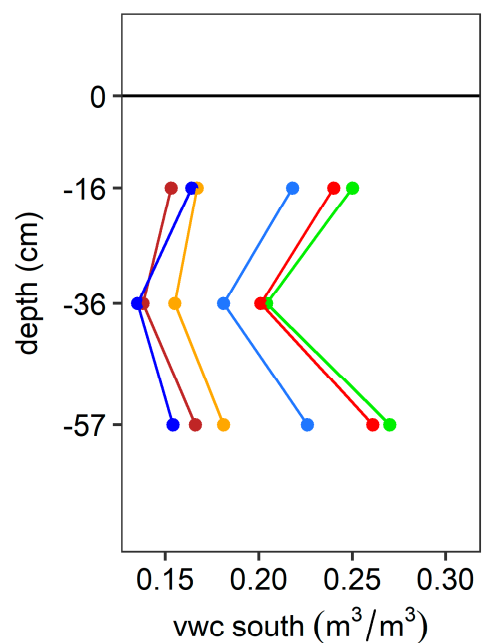

(b)

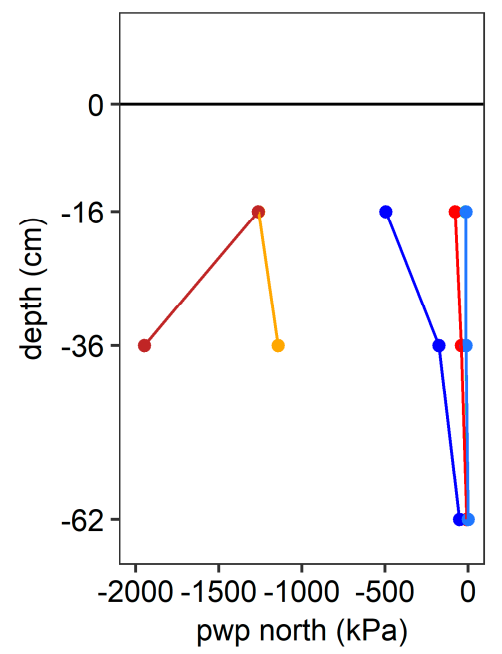

(e)

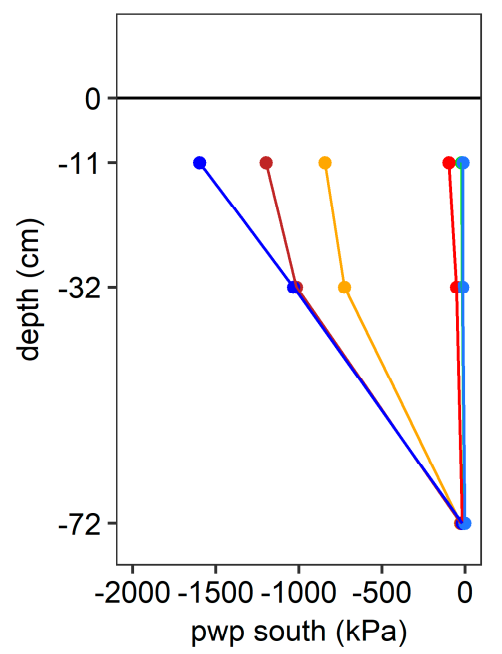

(c)

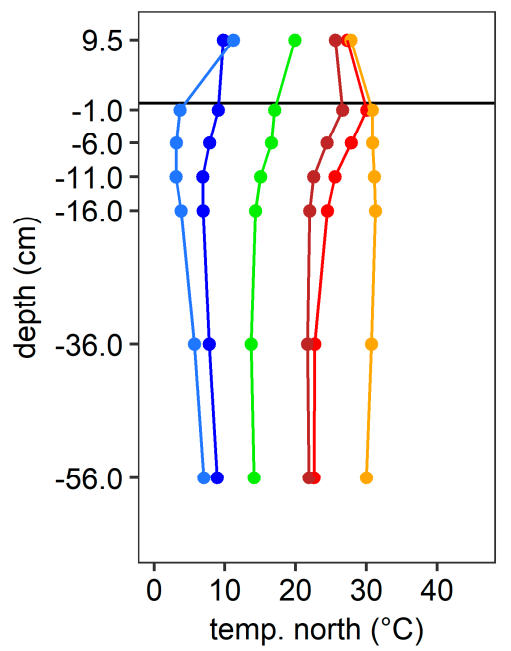

(f)

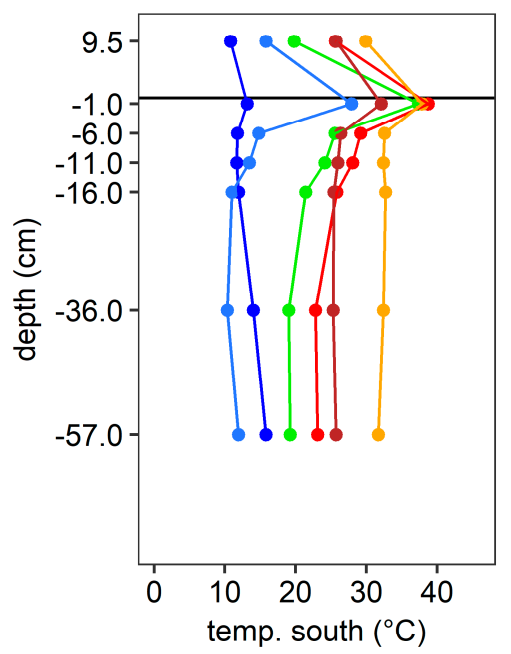

$\rightarrow 08 / 04 / 201712: 00-0-08 / 08 / 201711: 30 \rightarrow 08 / 12 / 201712: 00$

$\rightarrow$ 08/06/2017 12:00 $\rightarrow$ 03/10/2017 11:35 - - 10/02/2018 12:00

Figure 15. Temporal variation of the variations in volumetric water content (VWC), pore water pressure (PWP), and temperature (temp.) with depth at the North and South bare profiles. The data are represented in two-month intervals from April 2017-February 2018. (a) Volumetric water content at North slope; (b) pore water pressure at North slope; (c) air and soil temperature at North slope; (d) volumetric water content at South slope; (e) pore water pressure at South slope; (f) air and soil temperature at South slope.

\section{Conclusions}

The monitoring of soil-vegetation-atmosphere interactions is a necessary but difficult task. The experience of installing and verifying the correct sensing of all devices confirms that the monitoring of so many different processes is complex in an outdoor experiment and strongly differs from laboratory tests, which are performed under controlled conditions. The correct calibration, adequate installation and permanent maintenance of the sensors is time-consuming, but fundamental. In our set-up, the most critical devices are the water-filled ceramic cup tensiometers, which de-saturated sometimes.

A good laboratory characterization of strength and hydrologic parameters is essential to understand correctly the infiltration process and to model the slope failure mechanisms. In this case, the laboratory tests indicate that there is a great contribution of suction to the shear strength. 
However, laboratory results may diverge from field observations, since heterogeneities are much more common in large experiments like this embankment. For example, in the trenches which were excavated at the four slope partitions, we observed cracks, fissures, and macropores that may have developed due to small displacements in the soil or due to root growing. All these features create preferential flow paths of the water and increase soil permeability and reduce suction and consequently also its strength. Therefore, permeability in the embankment is certainly much higher than the one measured in the laboratory (in the order of $10^{-8}$ and $10^{-7} \mathrm{~m} / \mathrm{s}$ ), which was obtained from a small homogeneous soil sample.

Preliminary analysis of the recorded data during the first year revealed the following outcomes regarding temperature and heat flux: (i) soil temperature strongly differs from North to South. (ii) At the terrain surface (sensors installed at $-1 \mathrm{~cm}$ ) of the South-facing slope, the temperatures are much higher (up to $55^{\circ} \mathrm{C}$ ) than the air temperature due to the solar radiation. This effect was not observed at the North-facing slope. (iii) A clear daily temperature fluctuation is visible at the most surficial sensors, while this effect is negligible at about $-50 \mathrm{~cm}$.

Regarding the rainfall infiltration, the results show: (i) high soil moisture during winter/spring and a dry period during summer and autumn. Only the most important rainfall, recorded on the 4th and 5th of February 2018 (90 mm rain in $30 \mathrm{~h}$ ), saturated the deepest soil layer at both North and South bare slopes. The highest drying rate took place during the month of June. (ii) There is a clear relationship between rainfall duration and intensity and the subsequent infiltration process. Most of the short duration rainfalls did not trigger significant variations in terms of VWC and PWP at all depths. In contrast, long duration rainfalls triggered a sharp increase on both VWC and PWP, while this effect decreases with depth.

All the monitored data will improve the understanding of the soil-vegetation-atmosphere interactions. Furthermore, the records provide essential input data for numerical modelling of the coupled thermo-hydro-mechanical processes in geological media and will serve to validate the SVA models with the aim of applying them to natural slopes of the Pyrenees.

Author Contributions: The laboratory tests were principally carried out by R.O. and A.F., and supervised by A.L. All the authors contributed to the design, installation and maintenance of the full-scale experiment, while the data analysis was mainly performed by R.O., M.H. and R.O. wrote the paper and the other authors reviewed it.

Funding: The study is funded by the national research project called "Slope mass-wasting under climate change (SMuCPhy)" granted by the Ministry of Economy and Competitiveness of Spain (project reference number BIA 2015-67500-R) and co-funded by AEI/FEDER, UE.

Acknowledgments: Alessandro Fraccica acknowledges the Marie Skłodowska-Curie ITN-ETN project TERRE 'Training Engineers and Researchers to Rethink geotechnical Engineering for a low carbon future' (H2020-MSCA-ITN-2015-675762). Enrique Romero, Miquel Masip (UPC Parc), Andrés Cevallos and Vinicio Guachizaca helped during field and laboratory tasks.

Conflicts of Interest: The authors declare no conflict of interest. The founding sponsors had no role in the design of the study; in the collection, analyses, or interpretation of data; in the writing of the manuscript, and in the decision to publish the results.

\section{References}

1. Gabarrón-Galeote, M.A.; Ruiz-Sinoga, J.D.; Quesada, M.A. Influence of aspect in soil and vegetation water dynamics in dry Mediterranean conditions: Functional adjustment of evergreen and semi-deciduous growth forms. Ecohydrology 2013, 6, 241-255. [CrossRef]

2. Coyle, D.R.; Nagendra, U.J.; Taylor, M.K.; Campbell, J.H.; Cunard, C.E.; Joslin, A.H.; Mundepi, A.; Phillips, C.A.; Callaham, M.A. Soil fauna responses to natural disturbances, invasive species, and global climate change: Current state of the science and a call to action. Soil Biol. Biochem. 2017, 110, 116-133. [CrossRef]

3. Drabo, A. Climate change mitigation and agricultural development models: Primary commodity exports or local consumption production? Ecol. Econ. 2017, 137, 110-125. [CrossRef] 
4. Imeson, A.C.; Lavee, H. Soil erosion and climate change: The transect approach and the influence of scale. Geomorphology 1998, 23, 219-227. [CrossRef]

5. Corominas, J. Landslides and climate. In Proceedings of the VIII International Symposium on Landslides, Cardiff, UK, 26-30 June 2000; Bromhead, E.N., Dixon, N., Ibsen, M.L., Eds.; Volume 4, pp. 1-33.

6. Intergovernmental Panel on Climate Change Climate Change 2013-The Physical Science Basis: Working Group I Contribution to the Fifth Assessment Report of the Intergovernmental Panel on Climate Change; Cambridge University Press: Cambridge, UK, 2014; ISBN 9781107057999.

7. Nearing, M.A.; Polyakov, V.O.; Nichols, M.H.; Hernandez, M.; Li, L.; Zhao, Y.; Armendariz, G. Slope-velocity equilibrium and evolution of surface roughness on a stony hillslope. Hydrol. Earth Syst. Sci. 2017, 21, 3221-3229. [CrossRef]

8. Panagos, P.; Meusburger, K.; Ballabio, C.; Borrelli, P.; Alewell, C. Soil erodibility in Europe: A high-resolution dataset based on LUCAS. Sci. Total Environ. 2014, 479-480, 189-200. [CrossRef] [PubMed]

9. Hovius, N.; Stark, C.P.; Allen, P.A. Sediment flux from a mountain belt derived by landslide mapping. Geology 1997, 25, 231-234. [CrossRef]

10. Alonso, E.; Lloret, A.; Romero, E. Rainfall induced deformations of road embackments. Riv. Ital. di Geotec. 1999, 33, 8-15.

11. Sajjan, A.K.; Gyasi-Agyei, Y.; Sharma, R.H. Rainfall-runoff modelling of railway embankment steep slopes. Hydrol. Sci. J. 2013, 58, 1162-1176. [CrossRef]

12. Briggs, K.M.; Loveridge, F.A.; Glendinning, S. Failures in transport infrastructure embankments. Eng. Geol. 2017, 219, 107-117. [CrossRef]

13. Blight, G.E. Interactions between the atmosphere and the earth. Geotechnique 1997, 47, 715-767.

14. Elia, G.; Cotecchia, F.; Pedone, G.; Vaunat, J.; Vardon, P.J.; Pereira, C.; Springman, S.M.; Rouainia, M.; Van Esch, J.; Koda, E.; et al. Numerical modelling of slope-vegetation-atmosphere interaction: An overview. Q. J. Eng. Geol. Hydrogeol. 2017, 50, 249-270. [CrossRef]

15. Tsiampousi, A.; Zdravkovic, L.; Potts, D.M. Soil-atmosphere interaction in unsaturated cut slopes. E3S Web Conf. 2016, 9, 8004. [CrossRef]

16. Tang, A.M.; Hughes, P.N.; Dijkstra, T.A.; Askarinejad, A.; Brenčič, M.; Cui, Y.J.; Diez, J.J.; Firgi, T.; Gajewska, B.; Gentile, F.; et al. Atmosphere-vegetation-soil interactions in a climate change context; impact of changing conditions on engineered transport infrastructure slopes in Europe. Q. J. Eng. Geol. Hydrogeol. 2018, 51, 156-168. [CrossRef]

17. Huang, C.-C.; Yuin, S.-C. Experimental investigation of rainfall criteria for shallow slope failures. Geomorphology 2010, 120, 326-338. [CrossRef]

18. Orense, R.P.; Shimoma, S.; Maeda, K.; Towhata, I. Instrumented Model Slope Failure due to Water Seepage. J. Nat. Disaster Sci. 2004, 26, 15-26. [CrossRef]

19. Tohari, A.; Nishigaki, M.; Komatsu, M. Laboratory Rainfall-Induced Slope Failure with Moisture Content Measurement. J. Geotech. Geoenviron. Eng. 2007, 133, 575-587. [CrossRef]

20. Moriwaki, H.; Inokuchi, T.; Hattanji, T.; Sassa, K.; Ochiai, H.; Wang, G. Failure processes in a full-scale landslide experiment using a rainfall simulator. Landslides 2004, 1, 277-288. [CrossRef]

21. Cooper, M.R.; Bromhead, E.N.; Petley, D.J.; Grants, D.I. The Selborne cutting stability experiment. Géotechnique 1998, 48, 83-101. [CrossRef]

22. Cui, Y.J.; Gao, Y.B.; Ferber, V. Simulating the water content and temperature changes in an experimental embankment using meteorological data. Eng. Geol. 2010, 114, 456-471. [CrossRef]

23. Glendinning, S.; Hughes, P.; Helm, P.; Chambers, J.; Mendes, J.; Gunn, D.; Wilkinson, P.; Uhlemann, S. Construction, management and maintenance of embankments used for road and rail infrastructure: Implications of weather induced pore water pressures. Acta Geotech. 2014, 9, 799-816. [CrossRef]

24. Ng, C.W.W.; Springman, S.M.; Alonso, E.E. Monitoring the Performance of Unsaturated Soil Slopes. Geotech. Geol. Eng. 2008, 26, 799-816. [CrossRef]

25. Bogaard, T.A.; van Asch, T.W.J. The role of the soil moisture balance in the unsaturated zone on movement and stability of the Beline landslide, France. Earth Surf. Process. Landforms 2002, 27, 1177-1188. [CrossRef]

26. Springman, S.M.; Jommi, C.; Teysseire, P. Instabilities on moraine slopes induced by loss of suction: A case history. Géotechnique 2003, 53, 3-10. [CrossRef] 
27. Rahardjo, H.; Rezaur, R.B.; Leong, E.C.; Alonso, E.E.; Lloret, A.; Gens, A. Monitoring and modeling of slope response to climate changes. In Proceedings of the 10th International Symposium on Landslides, $\mathrm{Xi}^{\prime}$ an, China, 30 June-4 July 2008; pp. 67-84.

28. Cassiani, G.; Boaga, J.; Rossi, M.; Putti, M.; Fadda, G.; Majone, B.; Bellin, A. Soil-plant interaction monitoring: Small scale example of an apple orchard in Trentino, North-Eastern Italy. Sci. Total Environ. 2016, 543, 851-861. [CrossRef] [PubMed]

29. Schmidt, K.M.; Roering, J.J.; Stock, J.D.; Dietrich, W.E.; Montgomery, D.R.; Schaub, T. The variability of root cohesion as an influence on shallow landslide susceptibility in the Oregon Coast Range. Can. Geotech. J. 2001, 38, 995-1024. [CrossRef]

30. Portilla, M.; Chevalier, G.; Hürlimann, M. Description and analysis of the debris flows occurred during 2008 in the Eastern Pyrenees. Nat. Hazards Earth Syst. Sci. 2010, 10, 1635-1645. [CrossRef]

31. Corominas, J.; Moya, J. Reconstructing recent landslide activity in relation to rainfall in the Llobregat River basin, Eastern Pyrenees, Spain. Geomorphology 1999, 30, 79-93. [CrossRef]

32. Gallart, F.; Clotet-Perarnau, N. Some aspects of the geomorphic processes triggered by an extreme rainfall event: The November 1982 flood in the Eastern Pyrenees. Catena Suppl. 1988, 13, 79-95.

33. Zhang, M.; Chen, F.Q.; Zhang, J.X. The Temporal Dynamics of Cynodon Dactylon Soil—Root System in Soil Conservation and Slope Reinforcement. Adv. Mater. Res. 2013, 838-841, 675-679. [CrossRef]

34. Chen, F.; Zhang, J.; Zhang, M.; Wang, J. Effect of Cynodon dactylon community on the conservation and reinforcement of riparian shallow soil in the Three Gorges Reservoir area. Ecol. Process. 2015, 4, 1-8. [CrossRef]

35. Garg, A.; Coo, J.L.; Ng, C.W.W. Field study on influence of root characteristics on soil suction distribution in slopes vegetated with Cynodon dactylon and Schefflera heptaphylla. Earth Surf. Process. Landforms 2015, 40, 1631-1643. [CrossRef]

36. Katritzidakis, M.; Liapis, A.; Stathakopoulos, I.; Pipinis, E.; Kekis, G.; Ververidou, E.; Sevastou, E. Erosion control by application of hydroseeding methods along the Egnatia Motorway (Greece). Eco-and Gr. Bio-Engineering Use Veg. Improv. Slope Stab. 2007, 103, 393-400. [CrossRef]

37. ASTM D6913/D6913M-17: Standard Test Methods for Particle-Size Distribution (Gradation) of Soils Using Sieve Analysis; ASTM International: West Conshohocken, PA, USA, 2017.

38. ASTM D7928-17: Standard Test Method for Particle-Size Distribution (Gradation) of Fine-Grained Soils Using the Sedimentation (Hydrometer) Analysis; ASTM International: West Conshohocken, PA, USA, 2017.

39. ASTM D4318-17e1: Standard Test Methods for Liquid Limit, Plastic Limit, and Plasticity Index of Soils; ASTM International: West Conshohocken, PA, USA, 2017.

40. ASTM D854-14: Standard Test Methods for Specific Gravity of Soil Solids by Water Pycnometer; ASTM International: West Conshohocken, PA, USA, 2014.

41. ASTM D3080/D3080M-11: Standard Test Method for Direct Shear Test of Soils Under Consolidated Drained Conditions; ASTM International: West Conshohocken, PA, USA, 2011.

42. Day, S.R.; Daniel, D.E. Hydraulic Conductivity of Two Prototype Clay Liners. J. Geotech. Eng. 1985, 111, 957-970. [CrossRef]

43. Fredlund, D.G.; Xing, A.; Fredlund, M.D.; Barbour, S.L. The relationship of the unsaturated soil shear to the soil-water characteristic curve. Can. Geotech. J. 1996, 33, 440-448. [CrossRef]

44. ASTM D7263-09(2018)e1: Standard Test Methods for Laboratory Determination of Density (Unit Weight) of Soil Specimens ASTM International: West Conshohocken, PA, USA, 2018.

45. Skempton, A.W. Long-Term Stability of Clay Slopes. Géotechnique 1964, 14, 77-102. [CrossRef]

46. Alonso, E.E.; Gens, A.; Josa, A. A constitutive model for partially saturated soils. Géotechnique 1990, 40, 405-430. [CrossRef]

47. Bishop, A.W. The principle of effective stress. Tek. Ukebl. 1959, 106, 859-863.

48. Schrefler, B.A. The Finite Element Method in Soil Consolidation (with Applications to Surface Subsidence). Ph.D. Thesis, University College of Swansea, Swansea, UK, 1984.

49. Fredlund, D.G.; Morgenstern, N.R.; Widger, R.A. The shear strength of unsaturated soils. Can. Geotech. J. 1978, 15, 313-321. [CrossRef]

50. Maksimovic, M. Nonlinear Failure Envelope for Soils. J. Geotech. Eng. 1989, 115, 581-586. [CrossRef] 
51. Sánchez Castilla, M. Thermo-Hydro-Mechanical Coupled Analysis in Low Permeability Media. Ph.D. Thesis, Universitat Politècnica de Catalunya, Barcelona, Spain, 2004.

52. Florides, G.; Kalogirou, S. Measurements of Ground Temperature at Various Depths. In Proceedings of the SET 2004, 3rd International Conference on Sustainable Energy Technologies, Nottingham, UK, 28-30 June 2004; pp. 1-6.

53. Horton, R.E. An Approach Toward a Physical Interpretation of Infiltration-Capacity. Soil Sci. Soc. Am. J. 1940, 5, 399-417. [CrossRef]

(c) 2018 by the authors. Licensee MDPI, Basel, Switzerland. This article is an open access article distributed under the terms and conditions of the Creative Commons Attribution (CC BY) license (http:/ / creativecommons.org/licenses/by/4.0/). 